\title{
MAPI: Model for Analysis and Projection of Inflation in France
}

\author{
Louis de Charsonville ${ }^{1}$, Thomas Ferrière $^{2}$ \& \\ Caroline Jardet ${ }^{3}$
}

August 2017, WP 637

\begin{abstract}
In this paper, we present the new model developed at Banque de France to forecast the Harmonized Index of Consumer Prices (HICP) and its components in France up to twelve quarters during the Eurosystem projection exercises. The model is a partial equilibrium model and is used for forecast purposes jointly with the macroeconomic model Mascotte. The model generates more accurate forecasts, conditional to Eurosystem common technical assumptions, than pure autoregressive models. We derive impacts of oil-price shock, exchange rate and wage shocks on headline and core HICP and find significant pass-through. ${ }^{4}$
\end{abstract}

Keywords: forecasting, inflation, time-series

JEL classification: E37 C32 E31 C53

${ }_{1}^{1}$ Banque de France, louis.decharsonville@,banque-france.fr

2 Banque de France, thomas.ferriere@,banque-france.fr

3 Banque de France, caroline.jardet@,banque-france.fr

${ }^{4}$ We thank Jean-Francois Ouvrard, Matthieu Lemoine, Pierre Sicsic, Yannick Kalantzis, Hervé Le Bihan, Stephane Guéné as well as participants in the 2016 NIPE Workshop, June 2017 Working Group on Forecasting meeting at ECB and seminar participants at Banque de France for helpful comments and insightful discussions. We thank especially Béatrice Rouvreau for outstanding research assistance.

Working Papers reflect the opinions of the authors and do not necessarily express the views of the Banque de France. This document is available on publications.banque-france.fr/en 


\section{NON-TECHNICAL SUMMARY}

This paper documents the new Model for the Analysis and Projection of Inflation in France (MAPI). MAPI is the model used to forecast inflation in France during the Eurosystem projections exercise since December 2016 (https://www.banquefrance.fr/en/economics/macroeconomic-forecasts-france). It is used for both short-term horizon forecasts during the Narrow Inflation Projection Exercise (NIPE) and mediumterm horizon forecasts during Broad Macroeconomic Projection Exercise (BMPE), in interaction with the workhorse macroeconomic model Mascotte.

Compared to previous models, MAPI's improvements are done along two dimensions:

i. Macroeconomic developments are better taken into account ensuring a complete wage-price setup and consistent projections over all forecasts horizons.

ii. We produce disaggregated forecasts for the five main components of inflation (unprocessed food, processed food, manufactured products, energy and services) up to twelve quarters, improving the understanding of inflation dynamics.

We show that the model produces better forecasts than three benchmark models, a Phillips curve, an $\mathrm{AR}(4)$ and a random walk at the three different horizons, as illustrated by the figure below for the 12 quarters horizon.

\section{MAPI vs benchmark models}

\section{Distribution of forecast errors at 12-quarter horizon}

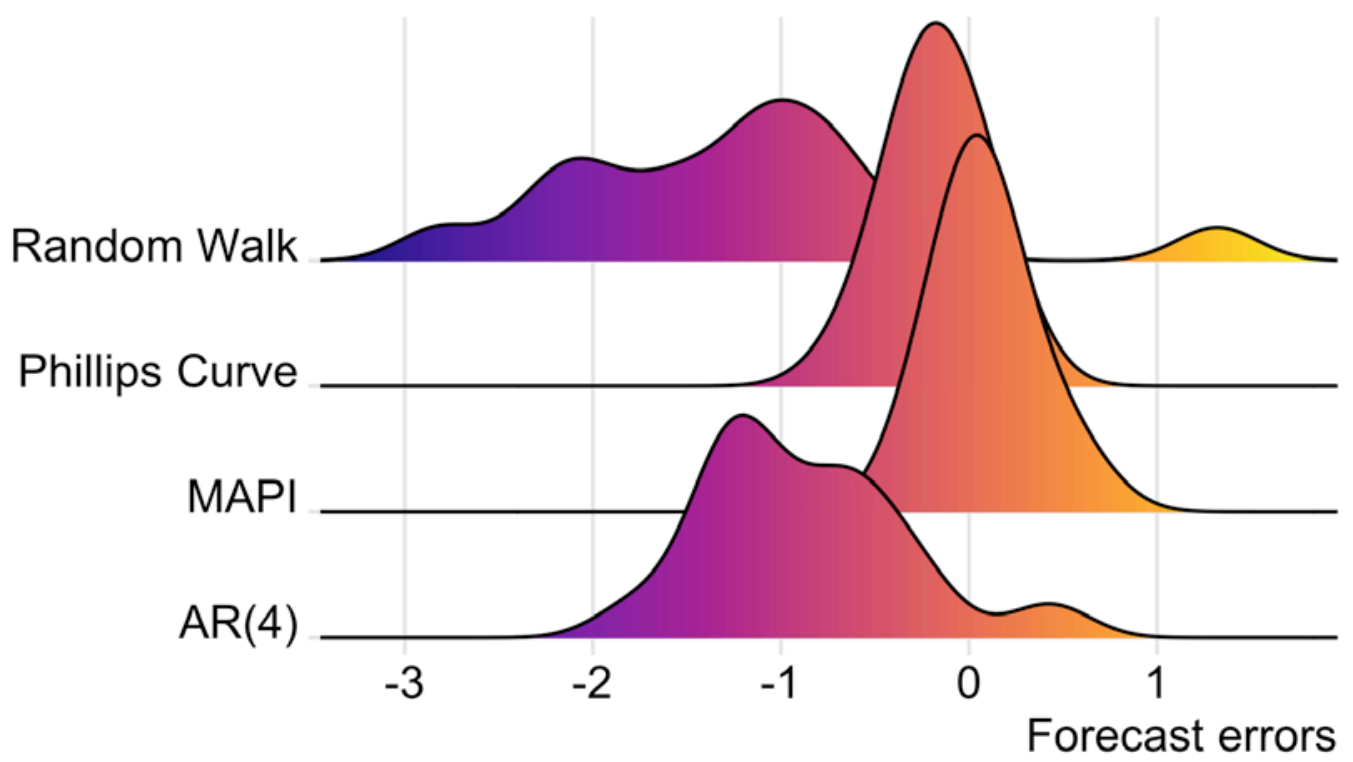

Comparison of the distribution of forecast errors from 2010Q1 to 2016Q4 at 12-quarter horizon for MAPI and benchmark models.

The paper also describes the transmission of shocks into HICP at its subcomponents, focusing on 4 standardized shocks: a shock on the national exchange rate, a shock on the euro dollar exchange rate, a shock on the price of crude oil and a shock in wage. Our simulations show that the transmission of shocks among the components of HICP. While our simulations evidence strong direct effects, notably for oil and euro dollar exchange 
rate, indirect effects are much more faded and diffuse slowly to components of HICP. Of course, given its partial equilibrium nature, MAPI has to be used as a complement to a full macroeconomic model such as Mascotte to get a complete simulation of the impact of the shocks on the French economy.

\title{
MAPI: Modèle pour l'Analyse et la Projection de 1'Inflation en France
}

\begin{abstract}
RÉSUMÉ
Nous présentons dans ce papier le nouveau modèle développé à la Banque de France pour la prévision de l'Indice des Prix à la Consommation Harmonisé (IPCH) et de ses sous-composantes pour un horizon de prévision allant jusqu'à 12 trimestres. Le modèle est un modèle d'équilibre partiel dont le bouclage macroéconomique est assuré via des itérations avec le modèle macroéconomique Mascotte. Nous proposons une analyse de la transmission de chocs de taux de change, de prix du pétrole et de salaire aux composantes de l'IPCH. Enfin, nous montrons que le modèle présente de meilleures performances prédictives que les modèles usuels de séries temporelles.
\end{abstract}

Mots-clés : prévisions, inflation, séries temporelles.

Les Documents de travail reflètent les idées personnelles de leurs auteurs et n'expriment pas nécessairement la position de la Banque de France.

Ce document est disponible sur publications.banque-france.fr 


\section{Introduction}

This paper describes the new forecasting model used at the Banque de France for projection of the Harmonized Index of Consumer Prices (HICP) in France: MAPI (Model for the Analysis and Projection of Inflation). The model is a disaggregated mark-up model that provide quarterly forecasts of the main HICP components.

The model must meet at least three criteria. First, it must be the reference model used to provide inflation forecasts for each Eurosystem projections exercise. Notably, two distinct Eurosystem exercises are performed. The first one, the Narrow Inflation Projection Exercise, is done at a quarterly frequency, and aims at providing monthly and not seasonally adjusted forecasts of HICP as well as its main five subcomponents and administered prices over a 12-month horizon. The second one, the Broad Macroeconomic Projection Exercise, is done twice a year (two of them coincide with the Narrow exercise). It aims at providing quarterly macroeconomic and inflation forecasts, over a longer horizon up to 12 quarters. An unique framework for inflation projections implies that our model must be able to provide monthly and quarterly (seasonally adjusted) projections for HICP and sub-components up to 12 quarters.

Second, our model must be able to incorporate a set of common Eurosystem international assumptions shared by all national central banks during each forecasting exercise. These assumptions include oil prices, exchange rates and commodity prices. In addition, the model must be able to fuel and incorporate domestic macroeconomic aggregates which are forecasted with the work-horse model used for the French economy, Mascotte. These interactions between both models ensure a complete wage-prices setup.

Third, the model must provide cogent economic assessment of recent and future inflation. For that purpose we have promoted the use of Error Correction Models (ECM). Hence, for each HICP sub-component, we model the long run and the short run dynamics. The long run equation is then interpreted as a long run equilibrium relationship between price level and its economic fundamentals. The model follows an empirical and disaggregated approach: HICP is split among sector-based sub-indexes which are then separately forecasted. Our prior is that the different components do not follow the same economic determinants and that disaggregation might help to produce more accurate forecasts. The disaggregated approach also captures more explicitly the transmission within the different HICP sub-indexes and provides consistent forecasts for core HICP and excluding energy HICP.

The model is drawn upon previous works by Célérier, 2009 and Jondeau, Le Bihan, and Sedillot, 1999. Célérier, 2009 detailed the forecasting model that was used previously. The model was split in two parts: a much disaggregated model (52 components) was used to forecast the first three months using statistical shorter term tools (ARIMA, seasonal forecasts); the next fifteen months were forecasted using univariate error correction models for a lesser number of components. Our model keeps the same distinction between the two horizons while subsequently reducing the number of components. Twenty one components are considered for the forecast up to three months and twelve components are forecasted for the next eleven quarters. The detailed breakdown for the short term forecasts allows introducing detailed information (calendar effects, change in legislation and taxes) in a fine-grained way. Our model also borrows from work by Jondeau et al., 1999. Jondeau et al., 1999 detail a parsimonious model of 5 univariate ECM forecasting French CPI. The paper is organized as follows: Section 2 provides the theoretical motivation behind the model. 
Section 3 details the framework, the disaggregation strategy and the data used. Section 4 presents the equations for each sub-indexes. Section 5 describes the impulse response functions derived from the model and discusses the transmission of shocks into inflation. Section 6 compared the forecast accuracy with three benchmark models.

\section{Theoretical motivation}

This section describes the modelling strategy adopted in the model. As the model is used for forecasting, the specification and the estimation are focused on predictive performance, data adequacy and parsimony. Nonetheless, a theoretical background is required to set forth a sound specification.

Final consumer prices $P_{c}$ are a weighted average of domestic prices, $P$, and import prices, $P_{i m p}$ :

$$
P_{c}=P^{\lambda} P_{i m p}^{1-\lambda}
$$

with $\lambda$ the share in volume of domestic goods and services in total consumption.

Domestic prices are set under monopolistic competition where firms have market power. Firms produce differentiated goods according to consumer tastes. The generic firm $j$ faces demand $Y(j){ }^{1}$.

$$
Y(j)=\left(\frac{P(j)}{P}\right)^{-\theta} Y
$$

where $\theta$ is the elasticity of substitution of consumers among goods and $P(j)$ the price of the variety $j$ produced by firm $j$. The generic firm maximizes its profit and at the optimum, pricing is a markup, $\mu$, over the marginal costs, $m c_{j}$ :

$$
P(j)=(1+\mu) m c_{j}
$$

At the equilibrium, all firms are identical and set their price at $P(j)$. The aggregate price writes:

$$
P=(1+\mu) m c
$$

The production function uses labor $L(j)$ with labor productivity $\Gamma$, and capital $K(j)$ with technology $A$. In a Cobb-Douglas framework, the production function writes:

$$
Y(j)=A K(j)^{\alpha}(\Gamma L(j))^{1-\alpha}
$$

And the marginal cost derived from the profit's maximization program writes:

$$
m c_{j}=\frac{1}{A} \frac{\tilde{r}}{\alpha} \frac{\tilde{w}}{\Gamma(1-\alpha)}^{1-\alpha}
$$

where $\tilde{r}$ and $\tilde{w}$ are the cost of capital and labor respectively. The marginal cost is log-linear in the cost of capital and labor. In a Leontief setup where production factors are not substitutable (energy

\footnotetext{
${ }^{1}$ The demand equation is obtained by positing that $\mathrm{Y}$ is a Dixit-Stiglitz aggregator of all the goods produced in the economy. See Dixit and Stiglitz (1977)
} 
for instance), the production function writes $Y(j)=A \min \left(\frac{K}{\alpha}, \frac{L}{\Gamma \beta}\right)$ and the marginal cost is linear in the cost of capital and the cost of labor ${ }^{2}$. Using (1), (4) and (6), we find:

$$
P_{c}=\left((1+\mu) \frac{1}{A} \frac{\tilde{r}}{\alpha} \frac{\tilde{w}}{\Gamma(1-\alpha)}^{1-\alpha}\right)^{\lambda}\left(P_{i m p}\right)^{1-\lambda}
$$

We log-linearize (7):

$$
p_{c}=c+\beta_{1} r+\beta_{2} w+\beta_{3} p_{i m p}
$$

where $r=\log (\tilde{r}), w=\log \left(\frac{\tilde{w}}{\Gamma}\right), c=\lambda \log \left(\frac{1+\mu}{A}\right)-\lambda \alpha \log (\alpha)-\lambda(1-\alpha) \log (1-\alpha), \beta_{1}=\lambda \alpha$, $\beta_{2}=\lambda(1-\alpha), \beta_{3}=1-\lambda$. Note that $\beta_{1}+\beta_{2}+\beta_{3}=1$.

The empirical strategy builds upon equation (8): fluctuations in the unit labor cost $w$ over the business cycle and change in import prices and in competition affects domestic prices. Therefore, we model each component as an error correction model where equation (8) specifies the long run relationship between prices, cost of production and markups.

\section{Data and Framework}

The model developed here is used for the inflation forecasts carried out within the Eurosystem. Moreover, the model also interacts closely with the macroeconomic model Mascotte. A wide variety of constraints on both the explanatory variables and the projections figures stems from this institutional framework.

First, the projections for France are part of an institutional framework which involves all the National Central Banks of the Eurosystem. In order to be consistent, the projections share a set of assumptions: crude oil prices, international food prices, international raw prices and exchange rates.

Second, although in most of aggregate macroeconomic models, inflation is given by the household consumption deflator, we forecast the consumer price index HICP and its five main components: unprocessed food, processed food, industrial goods excluding energy, energy and services. Each sub-component is forecasted separately, our prior being that they could be driven by different macroeconomics factors. They are then aggregated to provide headline HICP. This disaggregated approach is an institutional requirement, as it is needed for the short term exercise. In addition, analysis of sub-component forecasts might help to understand more accurately changes in future headline HICP, but also future excluding food and energy HICP (core HICP thereafter). We also split the main components between non-administered prices and administered prices 3 , as the latter mostly do not obey to economic determinants. For the first two months of the forecasts, we go further and use a very detailed disaggregation in 21 subcomponents to benefit from taxes announcement, calendar effects available in the short run. In the medium run, for forecast horizon up to 12 quarters, the disaggregation is less detailed. We forecast the main five components excluding administered prices and communications with services split in two between rents and other services (Table 11). Components are then aggregated based on HICP weights to produce the overall HICP.

Third, Eurosystem inflation short term projections are monthly and up to 11 months. Conversely while Eurosystem macroeconomic projections are quarterly and up to 12 quarters. Consequently,

\footnotetext{
${ }^{2}$ See Appendix E for a detailed explanation.

${ }^{3}$ See Appendix for a detailed split of the variables.
} 
our model should produce monthly forecasts for the first eleven months but also quarterly forecasts for the next 12 quarters to fuel the French macroeconomic model, Mascotte. In turn, the model must use macroeconomic variables from Mascotte so that the inflation forecasts are consistent with the macroeconomic projections. In practice, projections are the outcome of back-and-forth iterations between the two models until convergence is achieved. This setup permits to build detailed mediumrun inflation projections consistent with macroeconomic projections and ensure a complete wageprice setup. MAPI considered alone is then a partial equilibrium model. Therefore, effects of economic policies, such as monetary policy, are not explicitly integrated in MAPI. Nevertheless, their effects on HICP are taken into account in projection exercises via their impact in MAPI's input obtained from Mascotte.

Table 1: Disaggregation

\begin{tabular}{|c|c|c|c|c|}
\hline \multirow[b]{2}{*}{$\begin{array}{c}\text { Unprocessed food } \\
7.60 \%\end{array}$} & \multicolumn{2}{|l|}{ Short run - 2 months } & \multicolumn{2}{|c|}{ Medium run - 12 Quarters } \\
\hline & $\begin{array}{l}\text { Fruits } \\
\text { Vegetables } \\
\text { Meat and fish }\end{array}$ & $\begin{array}{l}1.10 \% \\
1.70 \% \\
4.80 \%\end{array}$ & Unprocessed food & $7.60 \%$ \\
\hline $\begin{array}{c}\text { Processed Food } \\
12.7 \%\end{array}$ & $\begin{array}{l}\text { Tobacco } \\
\text { Processed Food excluding to- } \\
\text { bacco }\end{array}$ & $\begin{array}{r}2.20 \% \\
10.50 \%\end{array}$ & $\begin{array}{l}\text { Tobacco } \\
\text { Processed food excluding to- } \\
\text { bacco }\end{array}$ & $\begin{array}{r}2.20 \% \\
10.50 \%\end{array}$ \\
\hline $\begin{array}{l}\text { Industrial goods } \\
\text { excluding energy } \\
26.60 \%\end{array}$ & $\begin{array}{l}\text { Pharmaceutical products } \\
(\mathrm{PP}) \\
\overline{\mathrm{Cl}} \overline{\text { lothing and shoes } \overline{(\mathrm{HC}} \overline{\mathrm{H}})} \\
\text { Industrial goods excluding } \\
\mathrm{PP} \text { and } \mathrm{HCH}\end{array}$ & $\begin{array}{r}2.00 \% \\
-\overline{4} . \overline{6} \overline{0} \% \\
20.00 \%\end{array}$ & $\begin{array}{l}\text { Pharmaceutical products } \\
\text { (PP) } \\
\text { Industrial goods } \\
\text { excluding PP }\end{array}$ & $\begin{array}{r}2.00 \% \\
----- \\
24.60 \%\end{array}$ \\
\hline $\begin{array}{l}\text { Energy } \\
9.00 \%\end{array}$ & $\begin{array}{l}\text { Petroleum products } \\
\text { Gas } \\
\text { Electricity }\end{array}$ & $\begin{array}{l}4.60 \% \\
1.80 \% \\
2.60 \%\end{array}$ & $\begin{array}{l}\text { Petroleum products } \\
\text { Gas } \\
\text { Electricity }\end{array}$ & $\begin{array}{l}4.60 \% \\
1.80 \% \\
2.60 \%\end{array}$ \\
\hline Services & $\begin{array}{l}\text { Combined passenger trans- } \\
\text { port } \\
\text { Passenger transport by road } \\
\text { Passenger transport by air } \\
\text { Passenger transport by sea } \\
\text { Insurance } \\
\text { Accomodation services } \\
\text { Others services }\end{array}$ & $\begin{array}{r}0.20 \% \\
1.50 \% \\
1.10 \% \\
0.10 \% \\
3.20 \% \\
1.80 \% \\
23.60 \%\end{array}$ & Private services & $31.50 \%$ \\
\hline & $\begin{array}{l}\overline{\text { Health }} \\
\text { Rents } \\
\text { Communication services }\end{array}$ & $\begin{array}{l}\overline{2} . \overline{5} \overline{\%} \overline{ } \\
7.00 \% \\
3.20 \%\end{array}$ & $\begin{array}{l}\text { Health } \\
\text { Rents } \\
\text { Communication services }\end{array}$ & $\begin{array}{l}\overline{2} . \overline{5} \overline{0} \% \\
7.00 \% \\
3.20 \%\end{array}$ \\
\hline
\end{tabular}

For the short-run forecasts, the nowcast is done using time series univariate methods like ARIMA augmented with expert judgment. For the medium-run forecasts, we use error-correction mode $\mathrm{I}^{4}$

\footnotetext{
${ }^{4}$ For each equation, we ensure that the variables were $\mathrm{I}(1)$ and cointegrated. Cointegration tests are detailed in Appendix $\mathrm{G}$
} 
with exogenous variables from the Eurosystem common set of assumptions and from the macroeconomic model Mascotte. The ECMs are estimated on quarterly seasonally adjusted data. The seasonal adjustment is done using a Kalman filter as in Harvey, Leybourne, and Newbold, 1997 with a break in 2011 to account for the structural change in the way of collecting seasonal indexes.

Table 2: Exogenous variables

\begin{tabular}{lll}
\hline Label & Source & Forecasts \\
\hline Crude oil price in dollars & Eurosystem & Futures \\
Refined oil price in dollars & Eurosystem & Model \\
Euro dollar exchange rate & Eurosystem & Random walk \\
Farm-gates prices & Eurosystem & Futures \\
Farm-gates prices - meat & Eurosystem & futures \\
Production cost in agricultural sector & National accounts & Model \\
Unit Labor Cost & Mascotte & Mascotte \\
Compensation per employee & Mascotte & Mascotte \\
Minimum wage (SMIC) & Mascotte & Mascotte \\
Real GDP & Mascotte & Mascotte \\
Unemployment rate & Mascotte & Mascotte \\
Imported goods excluding energy & Mascotte & Mascotte \\
Production of market services deflator & National accounts & Model \\
Excise tax on petroleum products (TICPE) & Ministry of Energy & Random walk + tax an- \\
& & nouncements \\
\hline
\end{tabular}

\section{Model and estimation}

This section details each equations used in the model. More precisely, 6 models are estimated: NEIG excluding pharmaceutical products, services excluding rents, communications and health services, rents, processed and unprocessed food and energy.

\subsection{Manufactured products}

Manufactured products component accounts for $26.6 \%$ of total HICP. We split manufactured products excluding energy in two: pharmaceutical products $(8 \%)$, which are semi-administered prices and mostly depend from social security budget act, from other non-energy industrial goods $(92 \%)$. We forecast pharmaceutical products by a random walk adjusted by expert judgment based on policy announcements. Conversely, manufactured products excluding pharmaceutical products are modelled through an ECM. As manufacturing is a highly competitive sector (Demmou, 2010), we assume that the law of one price holds. Hence, in the long run, domestic production's prices equals import'prices and (8) boils down to:

$$
p_{c}=c+\beta_{3} p_{i m p}
$$

This implies that a shock on the production's price of manufactured products has no effect on the final consumer price. Domestic producers absorb domestic production cost by adjusting their profit 
margin. We depart from (9) by adding the production's price of market services as a proxy measure for domestic retailing costs. Eventually, the long-term equation writes:

$$
p_{t}^{n e i g}=c_{l t}+\alpha p_{t}^{m}+(1-\alpha) * p_{t}^{p}+\epsilon_{t}
$$

where $p_{t}^{\text {neig }}$ is the log of the index of industrial goods excluding energy and pharmaceutical products, $p_{t}^{m}$ the log of price's index of imported goods excluding energy and $p_{t}^{p}$ the log of production's index price of market services. The estimation gives:

\begin{tabular}{lcc}
\hline & $c_{l t}$ & $\alpha$ \\
& $4.60^{* *}$ & $0.61^{* * *}$ \\
\hline Sample & 1996Q1 - 2014Q4 & \\
\hline Notes: ${ }^{* * *}:$ pvalue $<0.01,{ }^{* *}:$ pvalue $<0.05,{ }^{*}$ pvalue $<0.1$
\end{tabular}

The short term equation writes:

$$
\Delta p_{t}^{\text {neig }}=c_{s t}-\gamma \epsilon_{t-1}+\beta_{1} \Delta p_{t-2}^{n e i g}+\beta_{2} \Delta p_{t}^{p}+v_{t}
$$

One should note that the short term equation does not incorporate changes in import prices. We interpret this as evidence that the variable used in the model is prices of imported goods including non-consumer goods which might be less related to final consumer prices in the short run. The sample of estimation of the short run equations has been shortened in order to take into accounts the recent increase of the pass-through of international prices onto consumption prices.

\begin{tabular}{lcccc}
\hline & $c_{s t}$ & $\gamma$ & $\beta_{1}$ & $\beta_{2}$ \\
& $-0.002^{* *}$ & $0.13^{* * *}$ & $0.19^{*}$ & $0.44^{* * *}$ \\
\hline $\begin{array}{l}R_{2}=0.61 \\
\text { Sample }\end{array}$ & & & \\
\hline Notes: ${ }^{* * *}:$ pvalue $<007 \mathrm{Q} 3$ & $-2014 \mathrm{Q}{ }^{* *}$ : pvalue $<0.05,{ }^{*}$ pvalue $<0.1$
\end{tabular}

Fig. 1. Econometric contributions to manufactured products excluding pp

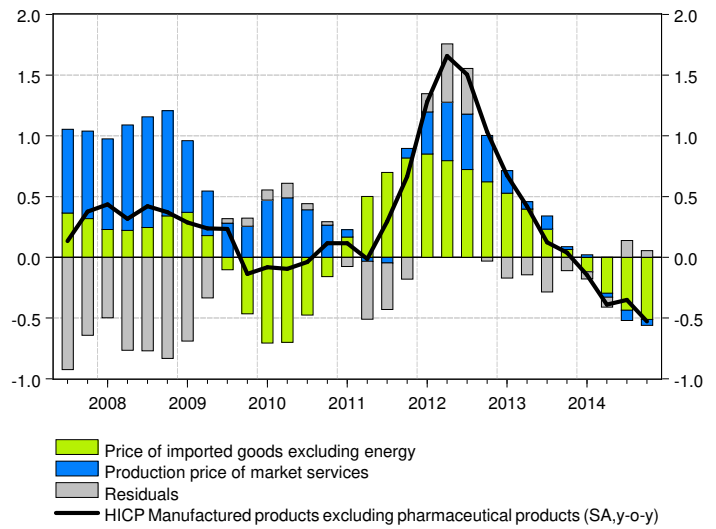

Fig. 2. Simulated and HICP manufactured products excluding $\mathrm{pp}$

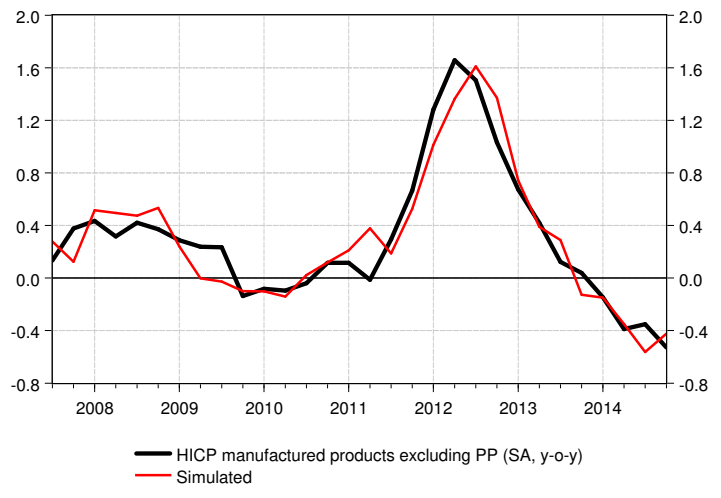


Production's index price of market services (in log) is also explicitly modelled in the long run as a function of unit labor cost in the private sector (in $\log , u l c$ ) and a trend that captures lower gains of productivity in services than in other sectors of the economy.

The long term equation writes:

$$
p_{t}^{p}=c_{l t}+u l c_{t}+\alpha t+\epsilon_{t}
$$

\begin{tabular}{lcc}
\hline & $c_{l t}$ & $\alpha$ \\
& $0.56^{* * *}$ & $6.5 e^{-4 * * *}$ \\
\hline$R_{2}$ & 0.70 & \\
Sample & $1998 \mathrm{Q} 1-2014 \mathrm{Q} 4$ & \\
\hline Notes: ${ }^{* * *}:$ pvalue $<0.01,{ }^{* *}:$ pvalue $<0.05,{ }^{*}$ pvalue $<0.1$
\end{tabular}

In the short run, change in GDP (in $\log , g d p$ ) is added to account for change in the business cycle. And the short run equation writes:

$$
\Delta p_{t}^{p}=c_{s t}-\gamma \epsilon_{t-1}+\sum_{i=1}^{4} \frac{\alpha_{i} \Delta p_{t-i}^{p}}{u l c_{t-i}}+\beta \Delta g d p_{t}+v_{t}
$$

\begin{tabular}{lccccccc}
\hline & $c_{s t}$ & $\gamma$ & $\alpha_{1}$ & $\alpha_{2}$ & $\alpha_{3}$ & $\alpha_{4}$ & $\beta$ \\
& $-0.002^{* * *}$ & $0.12^{* * *}$ & $-0.12^{* * *}$ & -0.10 & -0.22 & 0.04 & 0.65 \\
\hline$R_{2}$ & 0.55 & & & & & \\
Sample & $1998 \mathrm{Q} 1-2014 \mathrm{Q} 4$ \\
\hline Notes: ${ }^{* * *}:$ pvalue $<0.01,{ }^{* *}:$ pvalue $<0.05,{ }^{*}$ pvalue $<0.1$
\end{tabular}

Table 3 reports the impulse response functions of the price of manufactured goods excluding pharmaceutical products (PP) after a shock on exogenous variables. The pass-through of prices of imported goods excluding energy onto manufactured products is estimated to be $61 \%$. The transmission from imported goods' prices to consumer prices is spread over several years: $20 \%$ of the shock is passed onto consumer prices after the first year and $80 \%$ after three years. Conversely, consumer prices of manufactured products react quickly to production price of market services.

Table 3: Impulse response functions - Manufactured products

\begin{tabular}{lllllllll}
\hline $\begin{array}{l}\text { Manufactured products (excluding } \\
\text { PP) }\end{array}$ & Q1 & Q2 & Q3 & Q4 & 1A & 2A & 3A & LT \\
\hline$+1 \%$ on import prices & & & & & & & & \\
$+1 \%$ on production price of market & 0.44 & 0.51 & 0.51 & 0.49 & 0.49 & 0.46 & 0.42 & 0.39 \\
services & & & & & & & & \\
\hline
\end{tabular}

Notes: a $1 \%$ increase in import prices leads to an increase by $0.37 \%$ of HICP manufactured products after two years. 


\subsection{Services}

Services component accounts for $44.2 \%$ of total HICP. We split it in four categories: communications $(7.2 \%)$ since they follow a specific decreasing trend, health services $(5.7 \%)$ which are mostly administered, rents (15.8\%) which are partly indexed on past inflation (see Section 4.2.1) and others services, labelled "private services" (see 4.2.2) which include transportation services, accommodation services, maintenance and other miscellaneous services (71.3\%). In this subsection, we report the equations for rents and private services.

\subsubsection{Rents}

Rent 5 accounts for $7.1 \%$ of the total HICP. Rents in France are partly controlled: rents are set freely, but the annual increase cannot exceed the Housing Rent Reference Index year-on-year change. Since 2007Q4, the Housing Rent Reference Index (IRL thereafter) y-o-y equals the CPI inflation excluding rents and tobacco. Moreover, a significant part of rents are subsidized housing. Subsidized housing rents depend of the IRL and the tenant's income. In the long run, we expect rents to increase as housing prices. However, as housing prices are difficult to model and forecast in Mascotte, we use the quarterly change in the GDP as a proxy for the business cycle. The IRL definition had changed over time and as only the yearly change is legally binding, we specify the equation using the y-o-y change $\left(\Delta^{4}\right)$ of the IRL:

$$
\Delta p_{t}^{r e n t s}=c_{s t}+\alpha \Delta^{4} I R L_{t}+\beta \Delta g d p_{t}+\iota_{1} \delta_{2000}+\iota_{2} \delta_{2001}+\epsilon_{t}
$$

where $p_{t}^{\text {rents }}$ is the log of the rent component of HICP, $g d p_{t}$ the log of the real gdp, and $\delta_{2000}$ and $\delta_{2001}$ two dummies accounting for spurious change in the HICP rent index.

\begin{tabular}{|c|c|c|c|c|c|}
\hline & $\begin{array}{c}c_{s t} \\
0.001^{* * *}\end{array}$ & $\begin{array}{c}\alpha \\
0.17^{* * *}\end{array}$ & $\begin{array}{c}\beta \\
0.07^{*}\end{array}$ & $\begin{array}{c}\iota_{1} \\
-0.01^{* * *}\end{array}$ & $\begin{array}{c}\iota_{2} \\
-0.01^{* * *}\end{array}$ \\
\hline$R_{2}$ & \multicolumn{5}{|c|}{0.51} \\
\hline Sample & \multicolumn{5}{|c|}{ 1998M02 - 2016M02 } \\
\hline
\end{tabular}

\subsubsection{Private services}

Private services are mostly labor intensive and mostly depends on compensation per employee. The long run equation of private services writes:

$$
p_{t}^{\text {ser }}=c_{l t}+w_{t}+\alpha \delta_{2006 Q 4}+\beta \delta_{2006 Q 4} t+\mu\left(1-\delta_{2006 Q 4}\right) t+\epsilon_{t}
$$

where $p_{t}^{\text {ser }}$ is the log of the price's index of private services, $w_{t}$ the log of the compensation per employee in the whole economy and $\delta_{2006 Q 4}$ a dummy variable equals to 1 in the fourth quarter of 2006 and zero elsewhere aimed at capturing the structural change in the ratio price of services and compensation per employee.

\footnotetext{
${ }^{5}$ Rents in HICP include only actuals rentals paid by tenants and do not include imputed rentals for owner-occupied dwellings.
} 


\begin{tabular}{lcccc}
\hline & $c_{l t}$ & $\alpha$ & $\beta$ & $\mu$ \\
& $2.09^{* *}$ & $0.07^{* * *}$ & $-0.0011^{* * *}$ & $0.0007^{*}$ \\
\hline$R_{2}$ & 0.87 & & & \\
Sample & $1996 \mathrm{Q} 1$ & $-2014 \mathrm{Q} 4$ \\
\hline Notes: & ***: pvalue $<0.01,{ }^{* *}:$ pvalue $<0.05,{ }^{*}$ pvalue $<0.1$
\end{tabular}

Fig. 3. Ratio HICP private services and compensation per employee whole economy

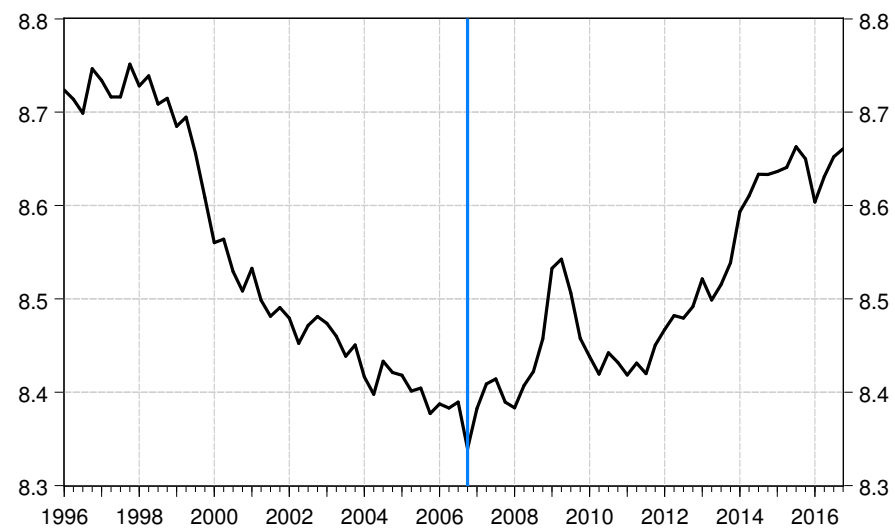

In the short run, prices of consumer's services depend on the minimum wage, the unemployment rate and VAT changes. Transportation services by air or by road also depend of crude oil's price:

$$
\begin{aligned}
\Delta p_{t}^{\text {ser }} & =c_{s t}-\gamma \epsilon_{t-1}+\phi \Delta p_{t-1}^{\text {ser }}+\alpha u_{t-2}+\beta_{1} \Delta S M I C_{t}+\beta_{2} \Delta S M I C_{t-1} \\
& +\chi \Delta P_{t-4}^{\text {brent }}+\rho_{1} \delta_{t v a, 2009}+\rho_{2} \delta_{t v a, 2012}+\rho_{3} \delta_{t v a, 2014}+v_{t}
\end{aligned}
$$

\begin{tabular}{lccccccc}
\hline & $c_{s t}$ & $\gamma$ & $\phi$ & $\alpha$ & $\beta_{1}$ & $\beta_{2}$ & $\chi$ \\
& $0.02^{* * *}$ & $0.09^{* * *}$ & $-0.08^{* * *}$ & -0.12 & $0.05^{* * *}$ & $0.02^{*}$ & $6.5 e^{-5}$ \\
& $\rho_{1}$ & $\rho_{2}$ & $\rho_{3}$ & & & & \\
& -0.001 & 0.0003 & $0.005^{* * *}$ & & & & \\
\hline$R_{2}$ & 0.55 & & & & & & \\
Sample & $1998 \mathrm{Q} 1-2014 \mathrm{Q} 4$ & & & & & \\
\hline
\end{tabular}

Notes: ${ }^{* * *}$ : pvalue $<0.01,{ }^{* *}$ : pvalue $<0.05,{ }^{*}$ pvalue $<0.1$

With $u_{t}$ denotes the unemployment rate, $S M I C_{t}$ the minimum wage, $P_{t}^{b r e n t}$ the price of Brent in euros, and $\delta_{T V A}$, dummies for VAT increases. 
Fig. 4. Econometric contributions - HICP Private services

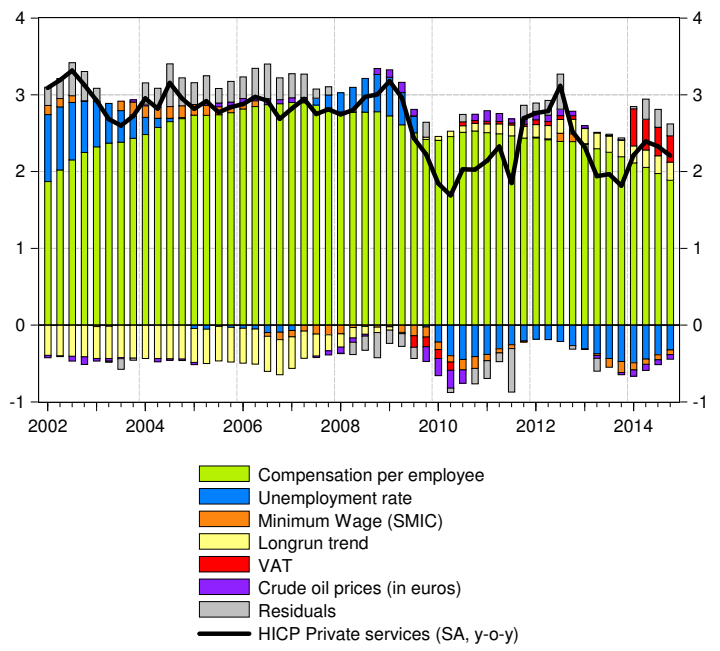

Fig. 5. HICP private services and simulated

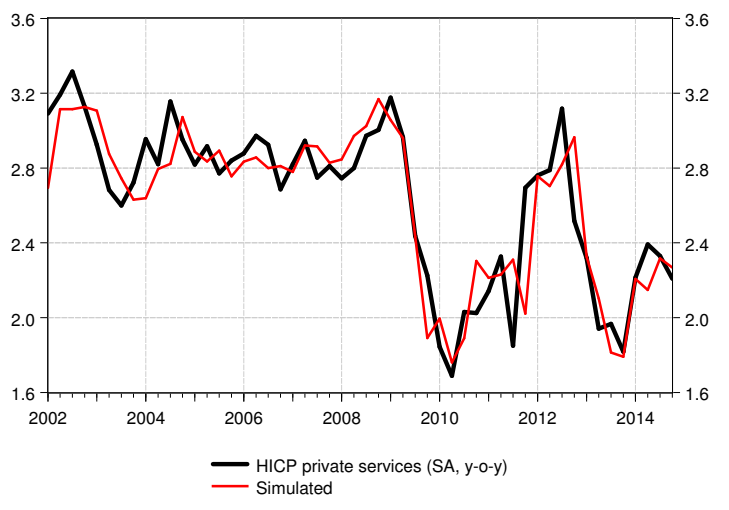

Table 4 reports the impulse response functions of shocks on exogenous variables. In the long run, the pass-through of wages onto services prices is estimated to be $100 \%$. A naïve shock on the minimal wage (SMIC) does not have an impact on HICP services in the long-run. However, an increase in the minimal wage is likely to affect compensation per employee since $10.5 \%$ of employees in the private sector earn the minimal wage (DARES, 2016) and because a hike in the minimal wage spillovers on other wages (Cette, Chouard, and Verdugo, 2012). Note that unemployment rate does not appear in the long run equation because it is stationary and therefore not cointegrated with private services index. However, a shock on the unemployment rate has permanent effect on the level on the private services index as it enters in level in the short run equation.

Table 4: Impulse response functions - Services

\begin{tabular}{lcccccccc}
\hline $\begin{array}{l}\text { Manufactured products (excluding } \\
\text { PP) }\end{array}$ & Q1 & Q2 & Q3 & Q4 & 1A & 2A & 3A & LT \\
\hline$+1 \%$ on compensation per employee & 0.00 & 0.09 & 0.16 & 0.23 & 0.12 & 0.37 & 0.55 & 1.00 \\
$+1 \%$ on unemployment rate & 0.00 & 0.00 & -0.13 & -0.24 & -0.09 & -0.47 & -0.76 & -1.48 \\
$+1 \%$ on minimal wage & 0.05 & 0.07 & 0.06 & 0.05 & 0.06 & 0.04 & 0.03 & 0.00 \\
$+1 \%$ on minimal wage + spillover & 0.05 & 0.07 & 0.07 & 0.08 & 0.07 & 0.12 & 0.16 & 0.26 \\
effects & & & & & & & & \\
$+10 €$ on crude oil prices & 0.00 & 0.00 & 0.00 & 0.00 & 0.00 & 0.05 & 0.04 & 0.00 \\
\hline
\end{tabular}

\subsection{Energy}

Energy accounts for $9.0 \%$ of total HICP and is split among three components: petroleum products (52\%), electricity (29\%) and gas (19\%). Gas and electricity are mostly administered prices and are forecasted with a random walk augmented by seasonal adjustments. Petroleum products 
are forecasted in a two-step approach. First, refined products' prices, gasoline and diesel, are forecasted using crude oil prices. Then retail prices are forecasted using refined product's prices. We estimate two equations for refined products. The specification is an ECM since refined product's price and crude oil prices are cointegrated. We impose the long-term coefficient to be one as the high competitiveness on the market entails that the pass-through between crude oil prices and refined product's prices is 100\%. All estimations are done on level (and not log-level) on monthly data.

The equation for refined products writes:

$$
\Delta P_{t}^{r e f}=c_{s t}-\gamma\left(P_{t-1}^{r e f}-P_{t-1}^{b r e n t}\right)+\alpha_{1} \Delta P_{t}^{\text {brent }}+\alpha_{2} \Delta P_{t-1}^{\text {brent }}+\epsilon_{t}
$$

With $P_{t}^{r e f}$ the refined product's price and $P_{t}^{\text {brent }}$ the crude oil price, both in euros. Similarly, we estimate four equations for each retail fuel: diesel, domestic fuel, unleaded gasoline sp95 and unleaded gasoline sp98. The specification is also an ECM with a 1-1 relationship between refined product's prices and retail prices. We also add a trend to captures the steady increase of retail margins.

$$
\Delta P_{t}^{r e t a i l, H T}=c_{s t}-\gamma\left(P_{t-1}^{r e t a i l, H T}-P_{t-1}^{r e f}-\beta t_{t-1}\right)+\alpha_{1} \Delta P_{t}^{r e f}+\alpha_{2} \Delta P_{t-1}^{r e f}+\epsilon_{t}
$$

With $P_{t}^{r e t a i l, H T}$ the price without tax of retail fuel. Estimations are computed on monthly data, from 1999M01 to 2016M02 (see Appendix D for details). Both equations fit well the data and show that crude oil prices shocks are transmitted quickly onto retail prices. Specifications are in level to account for the fact that production function are Leontief which entails that output's price is linear in inputs' prices and that excise tax dampen the equivalence with a specification in log. The price with tax is obtained by:

$$
P_{t}^{\text {retail }, T T C}=\left(1+\tau_{t}^{V A T}\right)\left(P_{t}^{\text {retail }, H T}+\text { ticpe }_{t}\right)
$$

With $P_{t}^{\text {retail,TTC }}$ the price with tax of retail fuel, $\tau_{t}^{V A T}$ is the VAT rate and ticpe $_{t}$ the level of the excise tax for a given petroleum product. The monthly variation of the index of petroleum products is derived by taking the weighted average of change in retail prices.

$$
\Delta I_{t}^{\text {pet }}=\sum_{i=1}^{4} \frac{\omega_{i} \Delta P_{t}^{\text {retail }, T T C, i}}{P_{t}^{\text {retail }, T T C, i}}
$$

Note that all specifications are in levels, entailing a non-linear relationship between change on the crude oil prices and change of HICP petroleum products subcomponent. Thus, the impact of a shock by $x \%$ or by $y$ euros on crude oil's prices is non-linearly related to the level of crude oil's prices. Table 5 reports the impact on HICP petroleum products subcomponent of an increase by 10 euros on the price of crude oil. Table 5 highlights that the transmission to retail prices is done in no more than one quarter.

Table 5: Impact on HICP Petroleum Products (in pp) of a 10 euros shock on the price of crude oil

\begin{tabular}{lcccccccc}
\hline Crude oil price & Q1 & Q2 & Q3 & Q4 & 1A & 2A & $3 \mathrm{~A}$ & LT \\
\hline $30 €$ & 7.16 & 6.97 & 6.98 & 7.01 & 6.96 & 7.05 & 7.08 & 7.09 \\
$55 €$ & 6.01 & 5.84 & 5.85 & 5.87 & 5.84 & 5.90 & 5.93 & 5.94 \\
$85 €$ & 5.05 & 4.90 & 4.91 & 4.93 & 4.90 & 4.96 & 4.98 & 4.99 \\
$115 €$ & 4.37 & 4.23 & 4.24 & 4.26 & 4.23 & 4.28 & 4.30 & 4.31 \\
\hline
\end{tabular}




\subsection{Processed food}

Processed food accounts for $12.7 \%$ on total HICP and is split between tobacco $(21.7 \%)$ and other processed food products (cereals, beverages and diaries). Processed food's prices depend on raw materials' prices, labor costs and on regulation. Processed food's prices are highly determined by the retail sector legislation, through the behavior of profit margins as described in Célérier, 2009 and Askenazy and Weidenfeld, 2007. The specification is done in two steps. First, we estimate a production's price in the agri-food sector using farm-gates price and compensation per employee (whole economy) as exogenous variables. Second, we estimate an ECM on HICP processed food, seasonally adjusted using production's price in the agri-food sector, unit labor cost and a trend of the distortion from mass retail market price and prices in small-size shops as exogenous variables. The latter captures the change of the legal framework.

The long-term specification of the production's price in the agri-food sector writes:

$$
p_{t}^{\text {prodC1 }}=c_{l t}+\alpha p_{t}^{\text {farm }}+\beta w_{t}+\epsilon_{t}
$$

\begin{tabular}{lccc}
\hline & $c_{l t}$ & $\alpha$ & $\beta$ \\
& $3.09^{* * *}$ & $0.25^{* * *}$ & $0.14^{* *}$ \\
\hline$R_{2}$ & 0.93 & \\
Sample & $2000 \mathrm{Q} 1-2014 \mathrm{Q} 4$ \\
\hline \multicolumn{3}{l}{ Notes: ${ }^{* * *}$ : pvalue $<0.01,{ }^{* *}$ : pvalue $<0.05,{ }^{*}$ pvalue $<0.1$}
\end{tabular}

with $p_{t}^{\text {prodC1}}$ the log of the production's price in the agri-food sector, $p_{t}^{\text {farm }}$ the log of farm-gates prices, and $w_{t}$ the log of the compensation per employee.

The short term specification writes:

$$
\Delta p_{t}^{\text {prodC1 }}=c_{s t}-\gamma \epsilon_{t-1}+\psi \Delta p_{t-1}^{\text {farm }}+v_{t}
$$

\begin{tabular}{lccc}
\hline & $c_{s t}$ & $\gamma$ & $\psi$ \\
& $0.002^{* * *}$ & $0.20^{* * *}$ & $0.12^{* * *}$ \\
\hline$R_{2}$ & 0.70 & \\
Sample & $2000 \mathrm{Q} 1-2014 \mathrm{Q} 4$ & \\
\hline \multicolumn{2}{l}{ Notes: ${ }^{* * *}$ : pvalue $<0.01,{ }^{* *}$ : pvalue $<0.05,{ }^{*}$ pvalue $<0.1$}
\end{tabular}

We then use the production price in the agri-food sector to estimate the ECM for processed food. In the long run, processed food's prices depend of production price, retail costs and on the level of competition. We use production price in the agri-food as a proxy for production price, unit labor cost for retails costs and the ratio between prices in the large-retail sector and the small retail sector to account for change in competition in the retail sector 6 .

\footnotetext{
${ }^{6}$ The ratio between large-retail sector and small-retail sector is extended over the forecast horizon by a linear trend.
} 


$$
p_{t}^{b h t}=c_{l t}+\alpha p_{t}^{\text {prodC1}}+\beta u l c_{t}+\nu d_{c o m p, t}+\epsilon_{t}
$$

With $p_{t}^{b h t}$ the $\log$ of quarterly seasonally adjusted index of processed food excluding tobacco, $p_{t}^{\text {prodC } 1}$ the $\log$ of production price in the agri-food sector, $u l c_{t}$ the unit labor cost in the private sector and $d_{c o m p, t}$ the log of the ratio between prices in the large retail sector and prices in the small retail sector.

\begin{tabular}{lcccc}
\hline & $c_{l t}$ & $\alpha$ & $\beta$ & $\nu$ \\
& $4.94^{* * *}$ & $0.27^{* * *}$ & $0.75^{* * *}$ & $0.32^{*}$ \\
\hline$R_{2}$ & 0.98 & & & \\
Sample & $2000 \mathrm{Q} 1$ & $-2014 \mathrm{Q} 4$ \\
\hline
\end{tabular}

Notes: ${ }^{* * *}$ : pvalue $<0.01,{ }^{* *}$ : pvalue $<0.05,{ }^{*}$ pvalue $<0.1$

In the short run equation, we add a dummy to accounts for the Chatel law, $d_{c h a t e l, t}$, which leads to a substantial decrease in the price of processed food in 2007Q1.

$$
\Delta p_{t}^{b h t}=c_{s t}-\gamma \epsilon_{t-1}+\chi \Delta p_{t-1}^{b h t}+\alpha \Delta p_{t}^{\text {prodC1}}+\beta \Delta u l c_{t}+\nu d_{\text {chatel }, t}+v_{t}
$$

\begin{tabular}{lcccccc}
\hline & $c_{s t}$ & $\gamma$ & $\chi$ & $\alpha$ & $\beta$ & $\nu$ \\
& $4.81 e^{-4}$ & $0.18^{* * *}$ & $0.47^{* * *}$ & $0.16^{* * *}$ & $0.20^{*}$ & $-0.01^{* *}$ \\
\hline$R_{2}$ & 0.67 & & & & & \\
Sample & $2000 \mathrm{Q} 1-2014 \mathrm{Q} 4$ & & & & \\
\hline
\end{tabular}

Notes: ${ }^{* *}$ : pvalue $<0.01,{ }^{* *}$ : pvalue $<0.05,{ }^{*}$ pvalue $<0.1$

Fig. 6. Econometric contributions - HICP Processed food

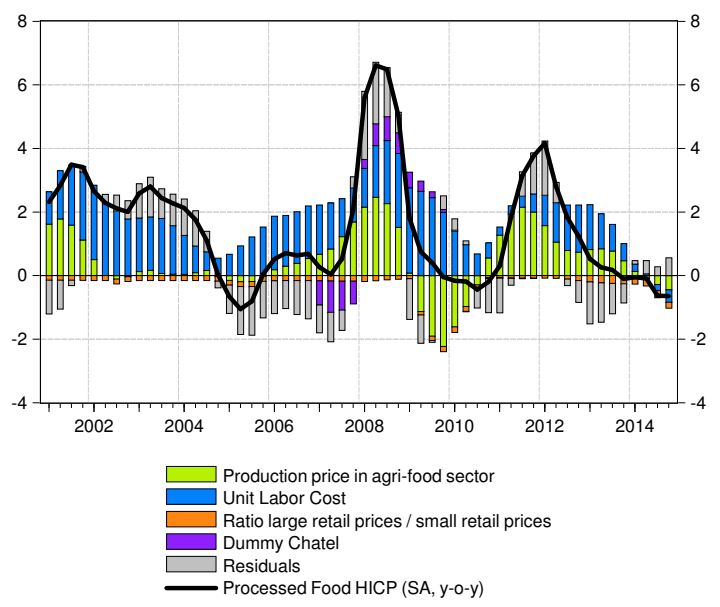

Fig. 7. HICP Processed food and simulated

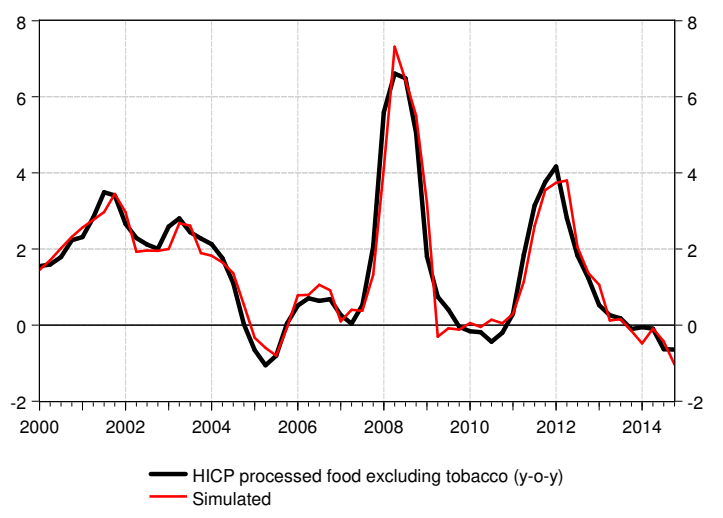


Table 6 reports impulse response functions of shocks on exogenous variables. Both production price and unit labor cost shocks are passed onto consumer prices within two years. Comparatively, farm-gates prices's shocks have a small effect on final consumer prices?

Table 6: Impulse response functions - Processed food

\begin{tabular}{lcccccccc}
\hline Processed food excluding tobacco & Q1 & Q2 & Q3 & Q4 & 1A & 2A & 3A & LT \\
\hline $\begin{array}{l}+1 \% \text { on production price in the agri- } \\
\text { food sector }\end{array}$ & 0.16 & 0.26 & 0.31 & 0.32 & 0.26 & 0.31 & 0.28 & 0.27 \\
$+1 \%$ on farm-gates prices & & & & & & & & \\
$+1 \%$ on unit labor cost & 0.00 & 0.03 & 0.05 & 0.06 & 0.04 & 0.07 & 0.07 & 0.07 \\
\hline
\end{tabular}

\subsection{Unprocessed food}

Unprocessed food index accounts for $7.6 \%$ of the total HICP and includes fruits (15\%), vegetables $(22 \%)$, meat $(51 \%)$ and fish (12\%). Fruits and vegetables' prices are mostly seasonal and linked to weather, making it difficult to forecast them in the long run. Conversely, meat prices are linked to international food prices. In the long run, the seasonally adjusted unprocessed food index is cointegrated with meat international food prices. The long run equation writes:

$$
p_{t}^{a}=c_{l t}+\alpha p_{t}^{\text {meat }}+\epsilon_{t}
$$

with $p_{t}^{a}$ the log of the monthly seasonally-adjusted unprocessed food HICP, $p_{t}^{\text {meat }}$ the $\log$ of meat on international food markets.

\begin{tabular}{lcc}
\hline & $c_{l t}$ & $\alpha$ \\
& $2.01^{* * *}$ & $0.52^{* * *}$ \\
\hline$R_{2}$ & 0.91 & \\
Sample & $1998 \mathrm{M} 01-2016 \mathrm{M} 02$ \\
\hline Notes: ${ }^{* * *}:$ pvalue $<0.01,{ }^{* *}$ : pvalue $<0.05,{ }^{*}$ pvalue $<0.1$
\end{tabular}

The short run equation writes:

$$
\Delta p_{t}^{a}=c_{s t}-\gamma \epsilon_{t-1}+\alpha \Delta p_{t}^{\text {meat }}+\chi_{1} \Delta p_{t-1}^{a}+\chi_{2} \Delta p_{t-2}^{a}+v_{t}
$$

\begin{tabular}{|c|c|c|c|c|c|}
\hline & $\begin{array}{c}c_{s t} \\
\left(6.10^{-4}\right)^{* * *}\end{array}$ & $\begin{array}{c}\gamma \\
0.02^{* * *}\end{array}$ & $\begin{array}{c}\chi_{1} \\
0.77^{* * *}\end{array}$ & $\begin{array}{c}\chi_{2} \\
-0.18^{* * *}\end{array}$ & $\begin{array}{c}\alpha \\
0.02^{*}\end{array}$ \\
\hline$R_{2}$ & 0.51 & & & & \\
\hline Sample & 1998M02 - & 016M02 & & & \\
\hline
\end{tabular}

\footnotetext{
${ }^{7}$ Between 2000Q1 and 2014Q4, the average quaterly change is 1.00\% in farm-gates prices and $0.39 \%$ in labor costs.
} 
The goodness of fit of the equation is relatively poor as half of the unprocessed food index is composed by fruits and vegetables prices whose prices are highly unpredictable. Table 7 reports the impact on unprocessed food of a shock on meat prices. An increase by $1 \%$ of meat prices induces an increase by $0.52 \%$ of HICP unprocessed food, in line with the weight of meat inside the HICP subcomponent.

Table 7: Impulse response functions - Processed food

\begin{tabular}{lcccccccc}
\hline Unprocessed food & Q1 & Q2 & Q3 & Q4 & 1A & $2 \mathrm{~A}$ & $3 \mathrm{~A}$ & $\mathrm{LT}$ \\
\hline$+1 \%$ on meat & 0.06 & 0.12 & 0.17 & 0.21 & 0.12 & 0.28 & 0.38 & 0.52 \\
\hline
\end{tabular}

\subsection{Administered prices}

Administered prices are sub-indexes that are not modelled with an explicit equation. Table 8 lists all the administered prices in the model. Tobacco is assumed to follow a random walk augmented with legal announcements. Pharmaceutical products are assumed to follow a declining trend adjusted by the savings announced in the social security budget act. Electricity, a semiadministered price, is assumed to follow a seasonal pattern in the medium run. In the short run, the forecast follows legal announcements. Gas is also a semi-administered price and is assumed to follow a seasonal pattern. Communications is no longer an administered price but has been falling from 1996 to 2013 and are stable from 2013 and are thus assumed to follow a random walk.

Table 8: Administered prices

\begin{tabular}{ll}
\hline Tobacco & $2.20 \%$ \\
Pharmaceutical products & $2.00 \%$ \\
Electricity & $2.60 \%$ \\
Gas and others & $1.80 \%$ \\
Communications & $3.20 \%$ \\
Heath services & $2.50 \%$ \\
\hline Total & $14.30 \%$ \\
\hline
\end{tabular}

\section{Inspecting the mechanisms}

In this section, we discuss how the model can capture the transmission of shocks into inflation. We estimate the pass-through of global shocks in components of domestic HICP components. In particular, building upon what is done among the Eurosystem, we do four standardized shocks: a shock on the national exchange rate, a shock on the dollar euro exchange rate, a shock on the price of crude oil and a shock in wages. Each shock is instantaneous and permanent, no transitory period and no return to baseline are assumed. Most of the exogenous variables are drawn from the macroeconomic model for French economy, Mascotte, and from a set of common variables used during the Eurosystem macroeconomic forecasting exercises (oil prices, exchange rates). These variables are likely to be affected by global shocks hitting the economy. Therefore, we use basic 
model elasticities (BMEs) from Mascotte and additional equations on top of the model equations. However, we do not model feedback effects on prices of increases in wages and rents. These effects are lower that the BMEs computed for the same shocks using Mascotte which incorporate indirect and second round effects.

\subsection{National exchange rate excluding dollar shock}

In this section, we assess how the model can seize the transmission into HICP component of a shock on the national effective exchange rate by $5 \%$ excluding dollar. This exercise aims at capturing the first round effects of the shock without second round effects. A shock on the national effective exchange rate impacts domestic inflation through import prices. The variables likely to be affected by the euro-exchange rate excluding dollar are:

- Import prices excluding energy in the manufactured products equation.

- Farm gates prices in the processed food equation.

Prices of imported goods excluding energy are taken from Mascotte. In order to model the impact of exchange rate shock on import prices through Mascotte equations, we use Mascotte's impulse response functions (see Figure 8). As exchange rate is not directly modelled in Mascotte, we use Mascotte's Basic Model Elasticities for a shock on the competitor's prices on the export side.

Fig. 8. Transmission of exchange price shocks

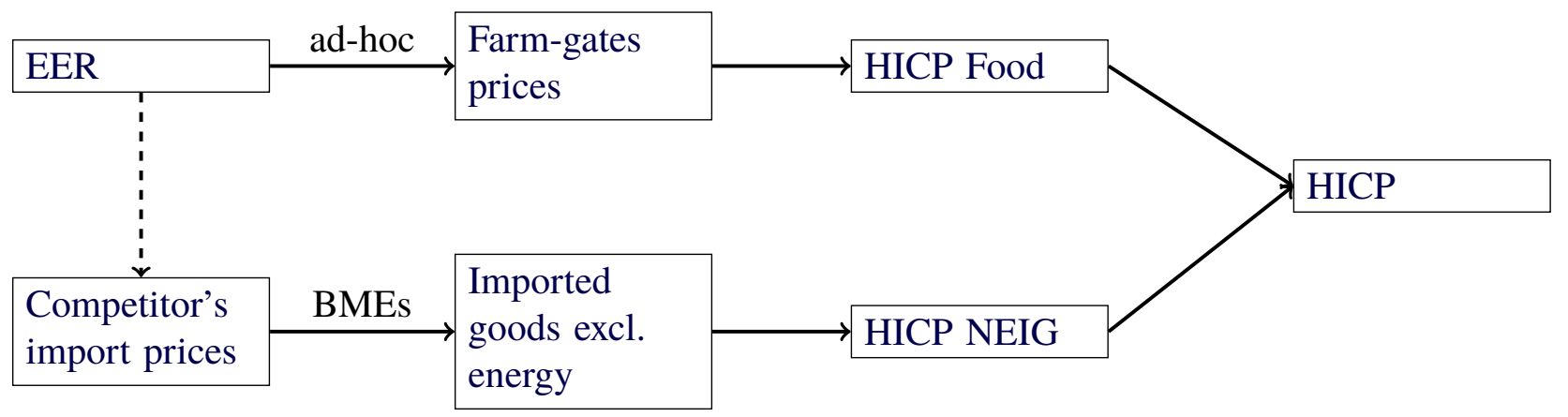

\subsubsection{Modelling farm gates prices}

Farm gates prices are taken from the set of Eurosystem assumptions for which we do not have any assessments of the pass-through of exchange rate. Farm gates prices are impacted by changes in commodities prices, changes in the exchange rate and changes in foreign demand for French goods and services. We estimate the following equation of farm-gates prices:

$$
\Delta p_{t}^{\text {farm }}=\alpha \Delta p_{t-1}^{\text {farm }}+\beta \Delta X_{t-2}^{\text {comm }}+\gamma \Delta \log E E R_{t}+\nu \Delta Y_{t}^{\text {world }}+v \Delta P_{t-3}^{\text {brent }}{ }^{\text {s }}+\eta \delta_{2007 Q 3}+\epsilon_{t}
$$

Where $p_{\text {farm }}$ is the log of farm-gates prices, $X_{t}^{\text {comm }}$ an index of imported food commodities' prices in foreign currencies in $\log _{\square}^{8} Y_{t}^{\text {world }}$ foreign demand for French goods and services (in log), $P_{t}^{b r e n t_{\$}}$

\footnotetext{
${ }^{8}$ The time series is published by Insee.
} 
the price of crude oil Brent in dollars, $E E R_{t}$ the weighted effective exchange rate against the 38 currencies of France's most important trading partners and $\delta_{2007 Q 3}$ a dummy equal to 1 in the third quarter of 2007.

\begin{tabular}{lcccccc}
\hline & $\alpha$ & $\beta$ & $\gamma$ & $\nu$ & $v$ & $\eta$ \\
& $0.28^{* *}$ & $0.20^{* * *}$ & $0.43^{* * *}$ & $0.36^{*}$ & $0.001^{* *}$ & $0.12^{* * *}$ \\
\hline$R_{2}$ & 0.55 & & & & & \\
Sample & $1998 \mathrm{Q} 3$ & $-2015 \mathrm{Q} 4$ \\
\hline
\end{tabular}

\subsubsection{Impulse response functions}

Table 9 reports the impacts derived from equations (11), (22), (27) of a 5\% appreciation of the effective exchange rate excluding the dollar on the HICP. Most of the impact stems from manufactured goods which prices would increase by $1.27 \mathrm{pp}$ after a $5 \%$ appreciation of the effective exchange rate.

Table 9: Elasticities to a shock on the effective exchange rate by $5 \%$

\begin{tabular}{lccccc}
\hline & $1 \mathrm{Q}$ & $4 \mathrm{Q}$ & $8 \mathrm{Q}$ & $12 \mathrm{Q}$ & Long term \\
Processed Food excl. t. (10.4\%) & 0.00 & -0.15 & -0.19 & -0.19 & -0.19 \\
Manufactured goods excl. PP (24.6\%) & 0.00 & -0.42 & -0.96 & -1.27 & -1.67 \\
\hline Total HICP & 0.00 & -0.12 & -0.26 & -0.33 & -0.43 \\
HICP excluding energy & 0.00 & -0.13 & -0.28 & -0.36 & -0.47 \\
HICP excluding food and energy & 0.00 & -0.15 & -0.33 & -0.44 & -0.58 \\
\hline
\end{tabular}

\subsection{Oil price shock}

In this section, we compute a 10 euros shock on crude oil price.

In our model, oil prices are explicitly taken into account in petroleum products equation for gasoline and diesel as well as in private services equations. However, an oil price shock is also likely to affect food and manufactured products components through an increase in the intermediate consumption along the production line. Imported goods are impacted by changes in the international environment by changes in prices of import of competitors. Competitors's prices on the import side is the index of prices of exported goods by France competitors on foreign markets weighted by the weight of each country in France import structure. It is used as a proxy for the aggregate price of imported goods. Indeed, an increase in crude oil prices impacts competitors's prices on the import side. We use equation (27) to model the impact of a shock on crude oil price on farm gates prices and we estimate an equation of competitor's prices on the import side to get the impact through on imported goods (see Figure 9). 
Fig. 9. Transmission of Brent's price shock onto HICP

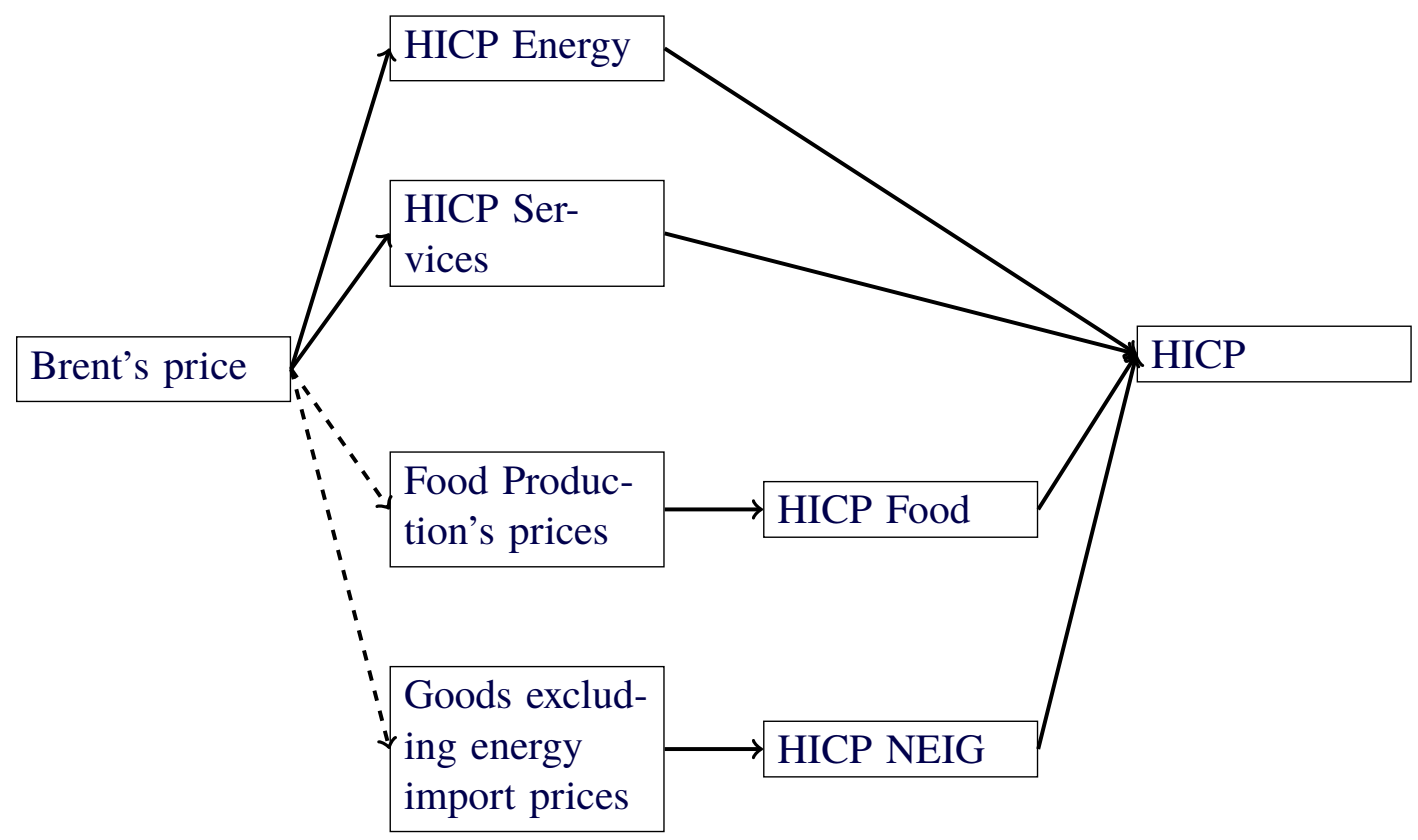

\subsubsection{Modelling competitor's prices on the import side}

Competitor's prices on the import side depends of crude oil prices, exchange rate, foreign demand and food commodities prices. We estimate the following equation:

$$
\Delta p_{t}^{c m d}=\alpha \Delta p_{t-1}^{c m d}+\beta \Delta \log E E R_{t}+\nu \Delta Y_{t}^{\text {world }}+v \Delta P_{t}^{\text {brent }}{ }_{\$}+\gamma \Delta X_{t}^{c o m m}+\epsilon_{t}
$$

Where $p_{t}^{c m d}$ is the log of quarterly inflation of competitor's import prices, $X_{t}^{c o m m}$ an index of imported food commodities' prices in foreign currencies in $\log ^{9}, Y_{t}^{\text {world }}$ foreign demand for French goods and services (in $\log$ ), $P_{t}^{\text {brent }}{ }_{\$}$ the price of crude oil Brent in dollars and $E E R_{t}$ the weighted effective exchange rate against the 38 currencies of France's most important trading partners.

\begin{tabular}{lccccc}
\hline & $\alpha$ & $\beta$ & $\nu$ & $v$ & $\gamma$ \\
& $0.12^{* *}$ & $0.97^{* * *}$ & $0.21^{* * *}$ & $0.0003^{*}$ & $0.05^{* * *}$ \\
\hline$R_{2}$ & 0.92 & & & & \\
Sample & $1996 \mathrm{Q} 1-2014 \mathrm{Q} 4$ & & \\
\hline
\end{tabular}

Notes: ${ }^{* * *}$ : pvalue $<0.01,{ }^{* *}:$ pvalue $<0.05,{ }^{*}$ pvalue $<0.1$

Competitor's import prices denominated in euro are highly correlated to the effective exchange rate. The coefficient of crude oil prices is relatively small but highly significant and large movement in crude oil prices impacts competitor's import prices (Figure 10.

We find that a shock by 10 euros on crude oil prices leads to an increase by $0.38 \mathrm{pp}$ of the competitor's prices on the import side. As transmission's delay is short, most of the pass-through

\footnotetext{
${ }^{9}$ The time series is published by Insee.
} 
is achieved during the first year (Figure 11). The impact of competitor's price on import prices is done using the basic model elasticities of the macroeconomic model Mascotte.

Fig. 10. Econometric contributions to competitor's prices on the import side dynamics

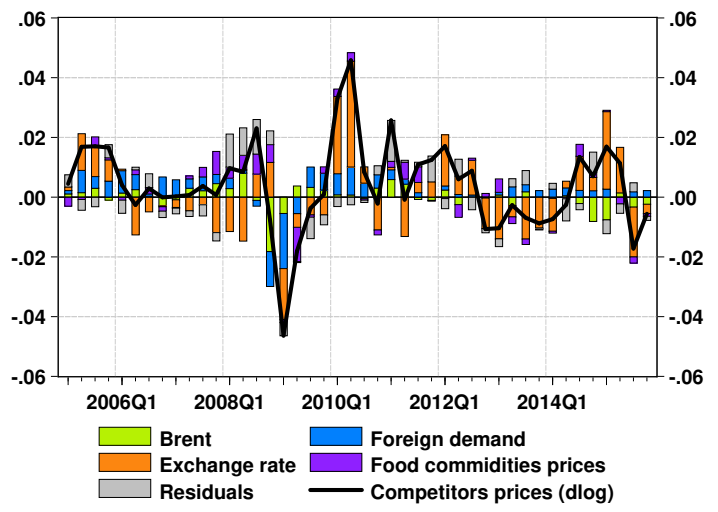

Fig. 11. Impact of a 10 euros shock on oil prices

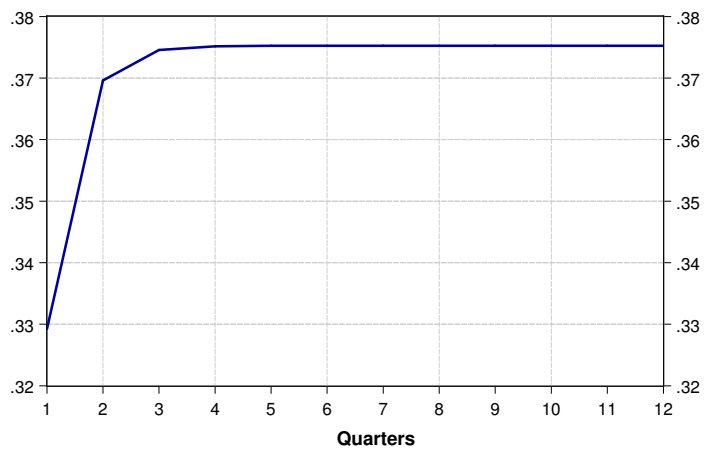

\subsubsection{Impulse response functions}

Direct effects of an oil price shock are computed using the impulse response functions of energy and services components. Due to excise tax and specification in level, the impact of a shock on crude oil barrel's price on retail oil price depends of the level of the crude oil barrel's price. Shocks are done for a barrel at 30, 55 and 85 euros. Conversely, the services inflation equation's specification is independent of the price level.

Indirect effects through food production are computed using equation (27). A 10 euros shock on crude oil price leads to an increase by $1.42 \mathrm{pp}$ of farm gate prices and eventually of an increase by $0.10 \mathrm{pp}$ of processed food prices.

Table 10 reports elasticities for a 10 euros increase of crude oil prices from the price level of 55 euros. Most of the impact stems from the energy component. Indirect effects through services and manufactured goods are much lower because transmission of shocks along the production line is slow and spread out. Consequently, total effects $(0.31 \mathrm{pp})$ are lower than impacts derived from accounting identities $(0.50 \mathrm{pp})$. We compare these results with the estimation derived from a rule of thumb for a 10 euros shock, using the following accounting identities:

$$
P^{C}=\frac{O}{C} P^{O}+\frac{Z}{C} P^{Z}
$$

where $P^{C}$ is HICP, $O$ the domestic consumption of petroleum products, $P^{O}$ the price of Brent, $C$ the household final consumption expenditure and $Z$ the household final consumption expenditure of goods and services excluding oil. Differentiating with respect to price of oil, we get:

$$
\frac{\Delta P^{C}}{P^{C}}=\frac{O \Delta P^{O}}{C} \frac{P^{C}}{P^{C}}
$$

We assume that $\frac{O}{C}$ is independent of oil prices and that pass-through is $100 \%$ in the medium run. An implicit assumption is domestic consumption of oil equals the oil's consumption by households. 
Given that household final consumption expenditure is 1070 billion of euros in 2013 and domestic consumption of oil products is 554 million of barrel, we find that $\frac{O}{C}=0.05$, implying that an oil price shock of 10 euros leads to an increase by $0.5 \mathrm{pp}$ of headline HICP.

Table 10: Impact of a 10 euros increase in crude oil prices (from the price level of 55euros)

\begin{tabular}{lccccc}
\hline & $1 \mathrm{Q}$ & $4 \mathrm{Q}$ & $8 \mathrm{Q}$ & $12 \mathrm{Q}$ & Long term \\
Processed Food excl. t. (10.4\%) & 0.00 & 0.00 & 0.09 & 0.10 & 0.10 \\
Manufactured goods excl. PP (24.6\%) & 0.00 & 0.03 & 0.08 & 0.10 & 0.13 \\
Energy (9.0\%) & 2.98 & 2.99 & 2.99 & 2.99 & 2.99 \\
Private services (31.4\%) & 0.00 & 0.00 & 0.05 & 0.03 & 0.00 \\
\hline Total HICP & 0.27 & 0.28 & 0.30 & 0.30 & 0.31 \\
HICP excluding energy & 0.00 & 0.01 & 0.03 & 0.04 & 0.05 \\
HICP excluding food and energy & 0.00 & 0.01 & 0.03 & 0.04 & 0.05 \\
\hline
\end{tabular}

\subsection{US Dollar exchange rate shock}

In this sub-section, we implement a permanent shock by $10 \%$ on the US dollar / euro exchange rate. As the US dollar / euro exchange rate is not explicitly modelled in any equations, the exercise is a linear combination of a shock on the national effective exchange rate and a shock on crude oil prices denominated in euro (see Figure 12).

Fig. 12. Transmission of a shock on the US dollar euro exchange rate

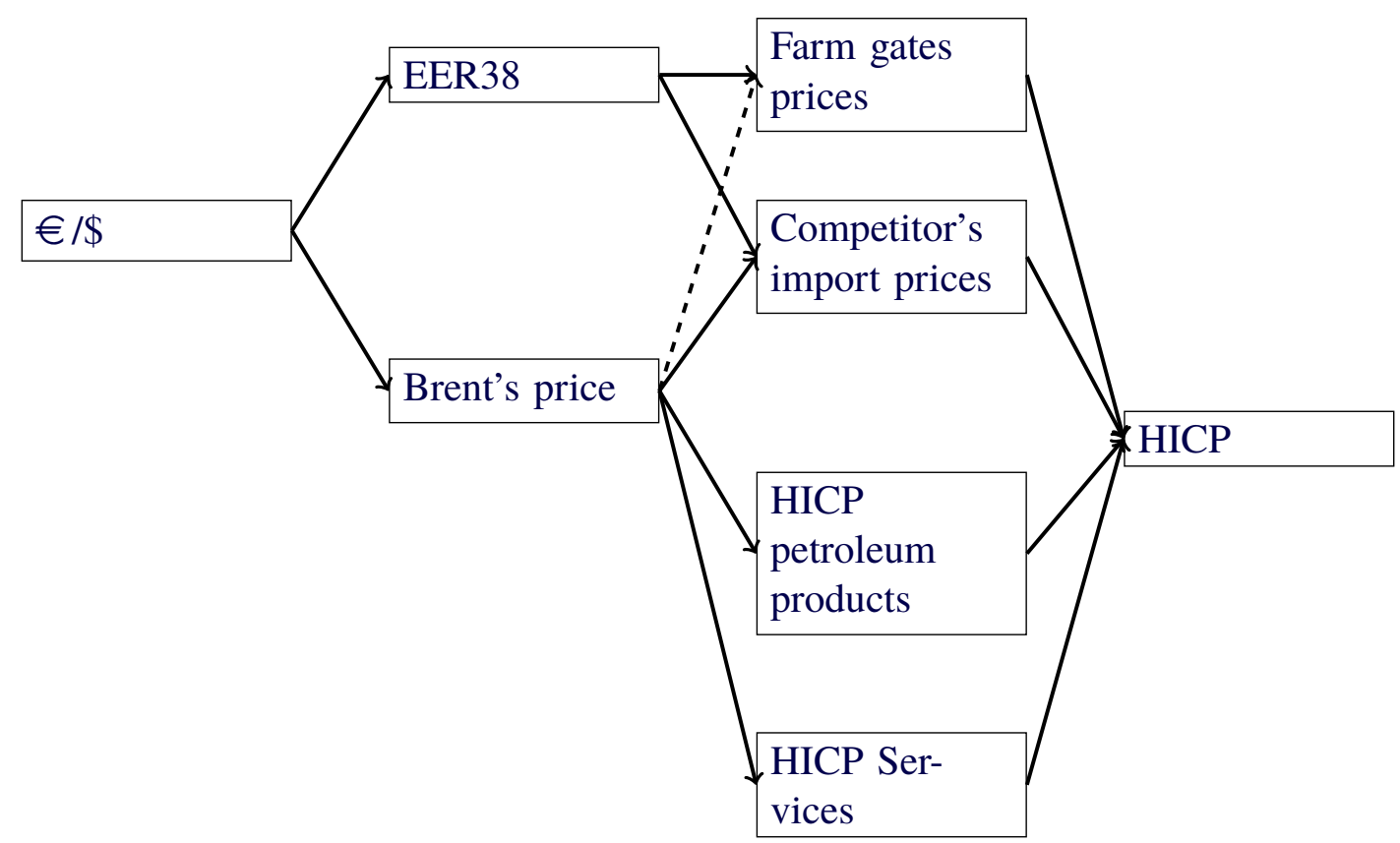

*EER38 is the weighted effective exchange rate against the 38 currencies of France's most important trading partners.

An increase by $10 \%$ of the US dollar euro exchange rate leads to an increase by $7.3 \%$ of the 
national exchange rate and a decrease by $10 \%$ of the crude oil prices. Since crude oil elasticities depend on the price level of crude oil, we report here the results for a barrel at 55 euros.

Table 11: Impact of a 10\% appreciation of the US dollar/euro exchange rate

\begin{tabular}{lccccc}
\hline & $1 \mathrm{Q}$ & $4 \mathrm{Q}$ & $8 \mathrm{Q}$ & $12 \mathrm{Q}$ & Long term \\
Processed Food excl. t. $(10.4 \%)$ & 0.00 & -0.02 & -0.08 & -0.08 & -0.08 \\
Manufactured goods excl. PP $(24.6 \%)$ & 0.00 & -0.08 & -0.19 & -0.26 & -0.34 \\
Energy $(9.0 \%)$ & -1.64 & -1.64 & -1.65 & -1.65 & -1.65 \\
Private services $(31.4 \%)$ & 0.00 & 0.00 & -0.02 & -0.02 & -0.02 \\
\hline Total HICP & -0.15 & -0.17 & -0.21 & -0.23 & -0.23 \\
HICP excluding energy & 0.00 & -0.03 & -0.08 & -0.10 & -0.10 \\
HICP excluding food and energy & 0.00 & -0.03 & -0.09 & -0.11 & -0.11 \\
\hline
\end{tabular}

Notes: Crude oil price level is set at 55 euros

Table 11 reports the estimation of the pass-through of a 10\% appreciation of the US dollar / euro exchange rate on HICP sub-components with the crude oil price set at 55 euros. Most of the impacts stems from the energy subcomponent through the induced decrease of crude oil price. Impact on manufactured goods prices is also substantial and arise from the decrease of competitors's prices on the import side.

\subsection{Wages shock}

In this subsection, we implement a permanent shock by $1 \%$ on wages. The model does not specify a wage equation and does not provide a complete wage price setting. Inflation model uses four different measures of wages: compensation per head, wages per head in the private sector only, the legal minimum wage (SMIC) and unit labor cost. We assume that real variables are not affected by changes in prices: real output and productivity do not react to a change in prices. We also assume that public sector wages remain constant. Conversely, we assume that the legal minimum wage is also increased by $1 \%$ (see Figure 13). Eventually, this boils down to assume that all the measures of wages throughout the model, either nominal or real, are increased by $1 \%$. 
Fig. 13. Transmission of a wage shock on HICP

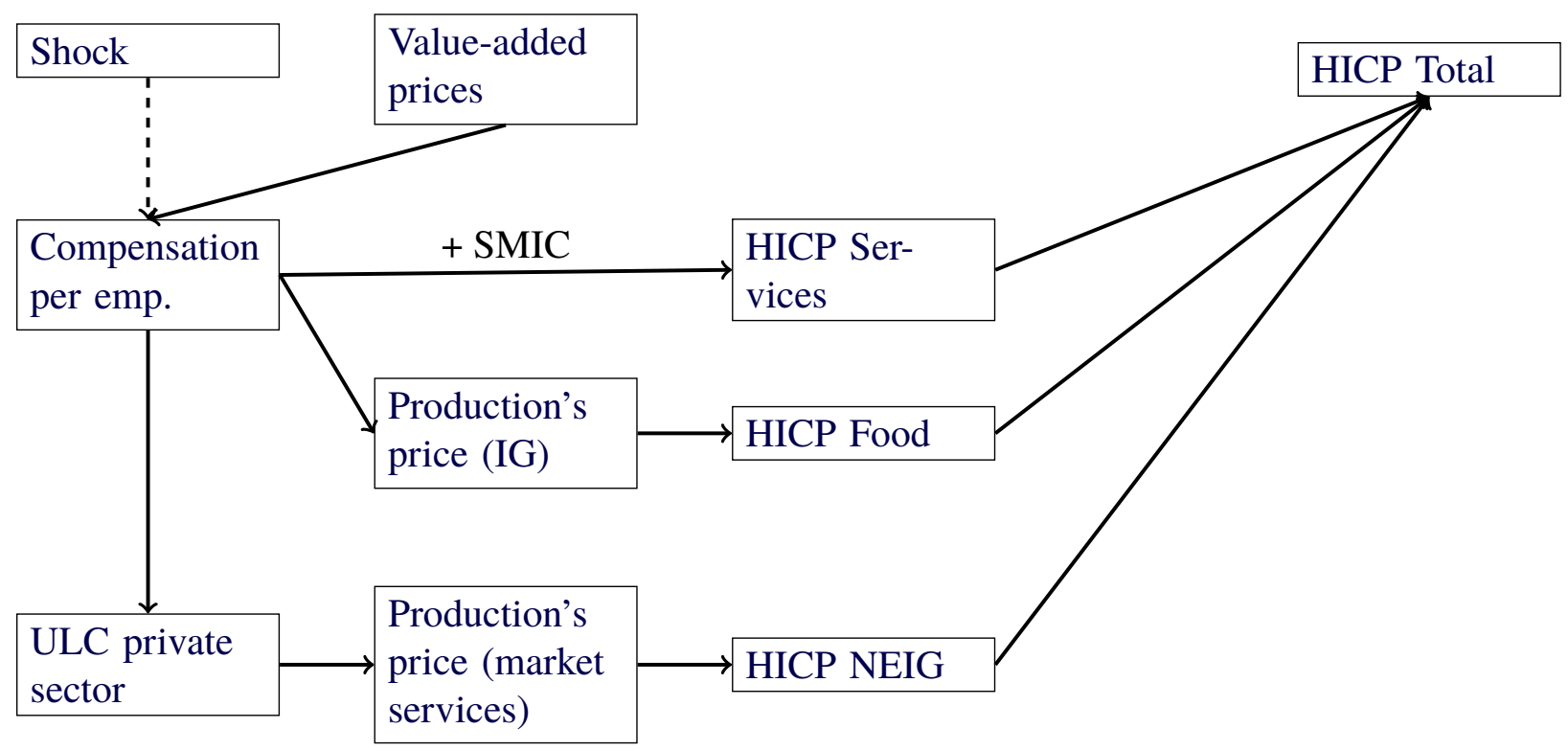

Without backwash-effects of wages on prices (second round effects), a 1\% increase of wages entails an increase of headline HICP by $0.41 \%$. Table 12 details the first round effects by components. Most of the impact stems from the services component since services' prices are anchored to nominal wages in the long run equation. A $1 \%$ increase in wages ultimately leads to an increase by $1 \%$ of services' prices. The minimum wage has no long run effects as it appears solely as a short run term in the equation. The impact through manufactured products and unprocessed food goes through the unit labor cost channel. In the long run, the pass-through of wages to processed food prices is $80 \%$, reflecting the intuition that processed food prices are labor-intensive. The long term reaction to a wage shock also highlights that the model is not designed as a general equilibrium model: in the long run, an increase by $1 \%$ of wages does not entail a $1 \%$ increase in prices. This is explained by the fact that the processed food and manufactured goods components are not anchored to nominal wages while administrative prices, the energy and unprocessed foods components are not linked to nominal wages.

Table 12: First round effects of wage shocks

\begin{tabular}{lccccc}
\hline & $1 \mathrm{Q}$ & $4 \mathrm{Q}$ & $8 \mathrm{Q}$ & $12 \mathrm{Q}$ & Long term \\
Processed Food excl. t. (10.4\%) & 0.20 & 0.68 & 0.81 & 0.80 & 0.79 \\
Manufactured goods excl. PP (24.6\%) & 0.44 & 0.49 & 0.44 & 0.41 & 0.39 \\
Private services (31.4\%) & 0.05 & 0.28 & 0.49 & 0.63 & 1.00 \\
\hline Total HICP & 0.14 & 0.26 & 0.31 & 0.33 & 0.41 \\
\hline
\end{tabular}




\section{Forecasting performance}

In this section, we compare our model's forecasts to three benchmarks models: a random walk, an 4-lag autoregressive equation, AR(4), and a Phillips curve (PC). We perform the analysis for headline inflation and for inflation excluding food and energy. We use MAPI with estimated equations as described in section 4. Both the autoregressive equation and the Phillips curve are estimated on the whole sample (1997Q1 to 2016Q4). The Phillips curve specification for headline inflation and excluding food and energy inflation includes a slack measure, the output gap, and a measure of imported inflation, relative price of imported goods and services for headline inflation, and relative price of imported goods excluding energy for core inflation. MAPI's and Phillips curve forecasts are computed conditionally to the observed path of the exogenous variables.

We compare forecasts from 2010Q1 to 2016Q4 at four different horizons: 1 quarter ahead, 4 quarters, 8 quarters and 12 quarters. Two statistics are computed: the Root Mean Square Error (RMSE) ${ }^{10}$, relatively to RMSE of the model, and the Diebold Mariano (DB) statistics. Since the number of observation is relatively small, we follow Harvey et al., 1997 and correct the Diebold Mariano Statistics for the bias. The p-value are computed by using a Student-t distribution with $\mathrm{T}-1$ degrees of freedom where $\mathrm{T}$ is the number of observations (26 for 1 quarter horizon, 23 for 4 quarters horizon, 19 for 8 quarters horizon and 15 for 12 quarters horizon). Figures (14) to (16) display the distribution of forecast errors on headline inflation across the three different horizons for MAPI and the benchmark models. Figures (17) to (22) compare the successive forecasts for each model with printed inflation.

Table 13 reports the root mean squared errors (RMSE) of the three benchmark models, relative to the RMSE of our model, in bold. It also reports the pvalue of the associated Diebold-Mariano test. A relative RMSE higher than one indicates that our model beats the benchmark model, whereas the pvalue indicates whether that improved performance can be considered statistically significant. Table 13 evidences that our forecast errors of the model are lower on average than errors of the three benchmark's models at all horizons and for both headline inflation and excluding food and energy inflation. Diebold Mariano tests indicate that the accuracy of our model's forecasts for headline inflation is significantly better than the AR(4)'s and the random walk's forecast although the test is inconclusive for the Phillips curve. Regarding inflation excluding food and energy, the model's forecasts are not significantly better than the AR(4) and the Phillips curve for inflation excluding food and energy.

Table 13 also highlights that short term forecasts (1 quarter ahead) are not significantly better than a Phillips curve. The results computed are pure model-based without any judgment nor addition of external information on future taxes development. This supports the need of disaggregated approach for the short run and expert judgment as done during the Eurosystem projection exercises. Indeed, the use of expert judgment for the first three months significantly has improved the forecasts 'accuracy.

\footnotetext{
${ }^{10} \mathrm{RMSE}$ at horizon $h$ for model $M$ is defined the standard deviation of errors of model $M$ at a given horizon $h$ : $R M S E^{M}(h)=\frac{1}{T_{h}} \sqrt{\sum_{t=2010 Q 1}^{2016 Q 4}\left(\Pi_{t}-\hat{\Pi}_{t, t-h}\right)^{2}}$ with $\Pi_{t}$ headline or core inflation observed at date $t$ and $\hat{\Pi}_{t, t-h}$ corresponding forecast computed at time $t-h$.
} 
Table 13: RMSE (relative) and Diebold-Mariano statistics

\begin{tabular}{|c|c|c|c|c|c|c|}
\hline \multirow[b]{2}{*}{ Horizon } & \multicolumn{3}{|c|}{ Headline } & \multicolumn{3}{|c|}{ Excluding food and energy } \\
\hline & $\operatorname{AR}(4)$ & Phillips Curve & Random Walk & $\operatorname{AR}(4)$ & Phillips Curve & Random Walk \\
\hline \multirow[t]{2}{*}{1} & 2.5 & 1.0 & 2.4 & 1.8 & 1.3 & 5.6 \\
\hline & 0.00 & 0.78 & 0.04 & 0.02 & 0.12 & 0.00 \\
\hline \multirow[t]{2}{*}{4} & 2.9 & 1.2 & 2.9 & 1.2 & 1.4 & 3.2 \\
\hline & 0.00 & 0.99 & 0.12 & 0.15 & 0.78 & 0.19 \\
\hline \multirow[t]{2}{*}{8} & 2.9 & 1.1 & 3.4 & 1.4 & 1.2 & 2.8 \\
\hline & 0.08 & 0.90 & 0.02 & 0.09 & 0.72 & 0.12 \\
\hline \multirow[t]{2}{*}{12} & 2.3 & 1.0 & 4.1 & 1.5 & 1.1 & 3.9 \\
\hline & 0.03 & 0.38 & 0.52 & 0.84 & 0.40 & 0.48 \\
\hline
\end{tabular}

Notes: relative RMSE are in bold, A RMSE superior to 1 indicates that the model outperforms the benchmark model on average. The pvalue of HLN-DM test is in italic, a p-value inferior to 0.05 is considered as indicating that the model's performance is significantly better than the benchmark model's performance.

\section{Conclusion}

We build a new model for forecasting inflation in France following a disaggregated approach of 12 sub-components. The model produces 12-quarters ahead forecasts and is to be used nested it into a general macroeconomic model. The disaggregated approach permits to decompose the contribution of inflation's subcomponents and to provide forecasts of core inflation at a medium run horizon. The model performs well, outperforming benchmark models. Its forecasting performance is comparable to a Phillips curve for both headline inflation and excluding food and energy inflation. 


\section{References}

Askenazy, P., Weidenfeld, K., 2007. Les soldes de la loi Raffarin. Paris, cepremap ed.

Célérier, C., 2009. Forecasting Inflation in France. Document de travail de la Banque de France 124.

Cette, G., Chouard, V., Verdugo, G., 2012. Les effets des hausses du Smic sur le salaire moyen. Economie et Statistique pp. 3-28.

Chatelais, N., Kalantzis, Y., de Gaye, A., 2015. Low inflation in the euro area: import prices and domestic slack. Rue de la Banque 06.

Chauvin, V., Devulder, A., 2008. An Inflation Forecasting Model for the Euro Area. Notes d'Etudes et de Recherches de la Banque de France.

DARES, 2016. La revalorisation du Smic au 1er janvier 2016. Tech. Rep. 068.

Demmou, L., 2010. La désindustrialisation en France. Documents de travail de la DG Tresor .

Diebold, F. X., Mariano, R. S., 1995. Comparing Predictive Accuracy. Journal of Business \& Economic Statistics .

Dixit, A. K., Stiglitz, J. E., 1977. Monopolistic Competition and Optimum Product Diversity. The American Economic Review 3, 297-308.

ECB, 2016. A guide to the Eurosystem/ECB staff macroeconomic projection exercises. Tech. rep.

Engle, R. F., Granger, C. W. J., 1987. Co-Integration and Error Correction: Representation, Estimation, and Testing. Econometrica 55, 251-276.

Granger, C. W. J., 1969. Investigating Causal Relations by Econometric Models and Cross-spectral Methods. Econometrica 37, 424-438.

Harvey, A. C., 1989. Forecasting, Structural Time Series Models and the Kalman Filter. Cambridge University Press, Cambridge.

Harvey, D., Leybourne, S., Newbold, P., 1997. Testing the equality of prediction mean squared errors. International Journal of Forecasting 13, 281-291.

Hubrich, K., Karlsson, T., 2010. Trade consistency in the context of the Eurosystem Projection Exercises. An overview. Occasional Paper Series .

Jondeau, E., Le Bihan, H., Sedillot, F., 1999. Modeling and Forecasting the French Consumer Price Index Components. Notes d'Études et de Recherches de la Banque de France 68.

Koopman, S. J., Franses, P. H., 2002. Constructing Seasonally Adjusted Data with Time-Varying Confidence Intervals. Oxford Bulletin of Economics and Statistics 64, 509-526. 


\section{Appendix A. Forecasts of MAPI and benchmark models}

Fig. 14. Distribution of headline inflation's forecast errors at 4 quarters per model MAPI vs benchmark models

Distribution of forecast errors at 4-quarter horizon

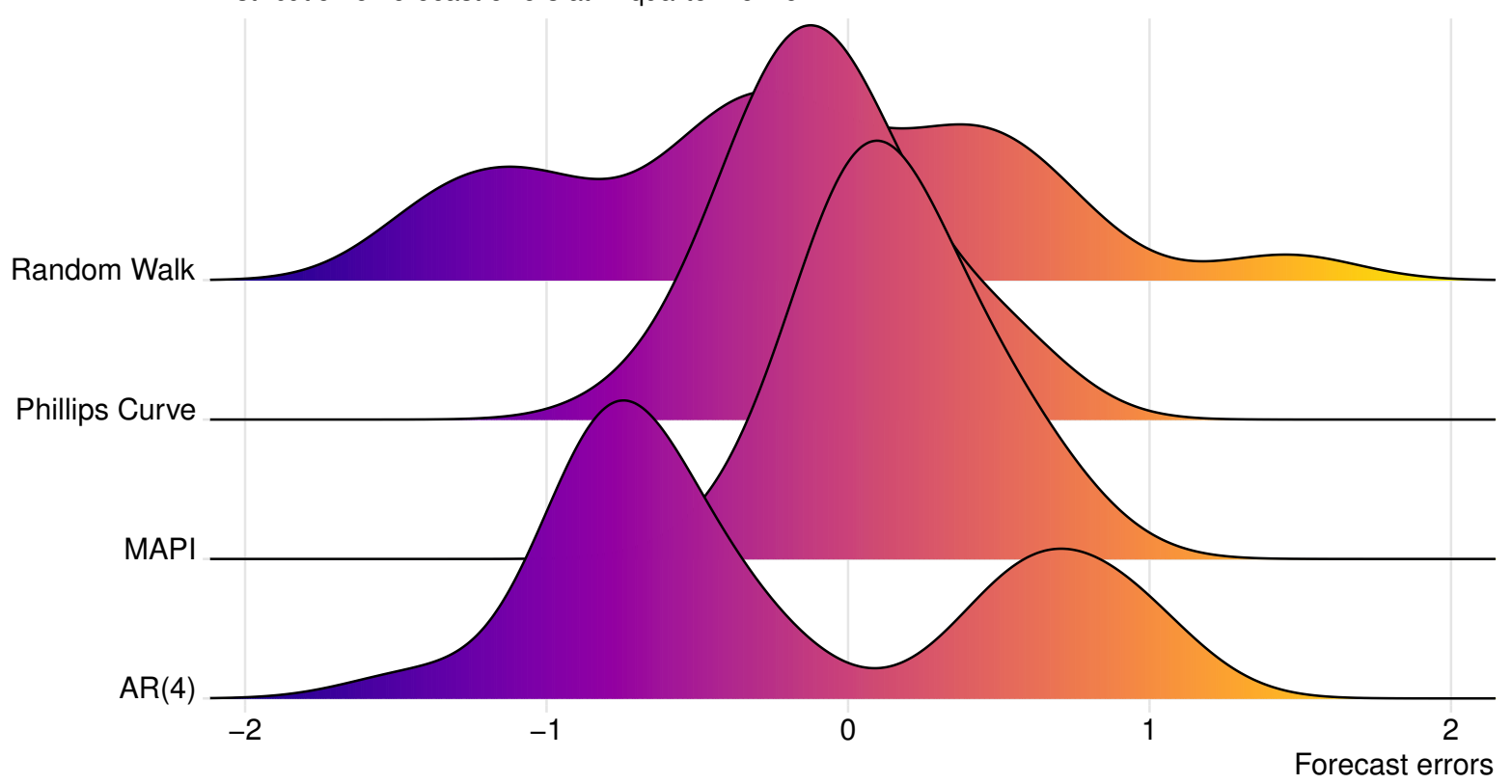

Comparison of the distribution of forecast errors from 2010Q1 to 2016Q4 at 4-quarter horizon for MAPI and benchmark models.

Fig. 15. Distribution of headline inflation's forecast errors at 8 quarters per model MAPI vs benchmark models

Distribution of forecast errors at 8-quarter horizon

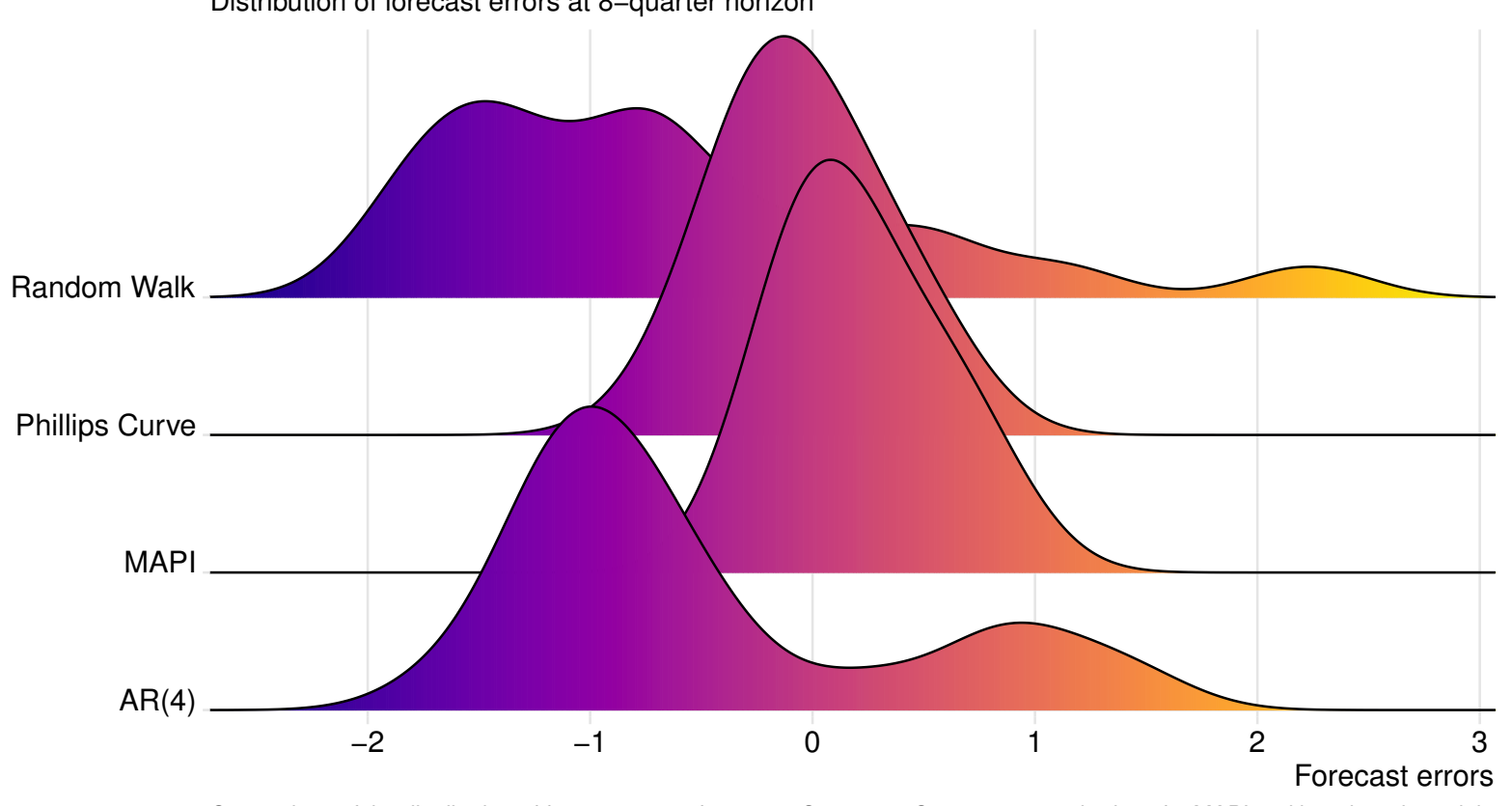

Comparison of the distribution of forecast errors from 2010Q1 to 2016Q4 at 8-quarter horizon for MAPI and benchmark models 
Fig. 16. Distribution of headline inflation's forecast errors at 12 quarters per model MAPI vs benchmark models

Distribution of forecast errors at 12-quarter horizon

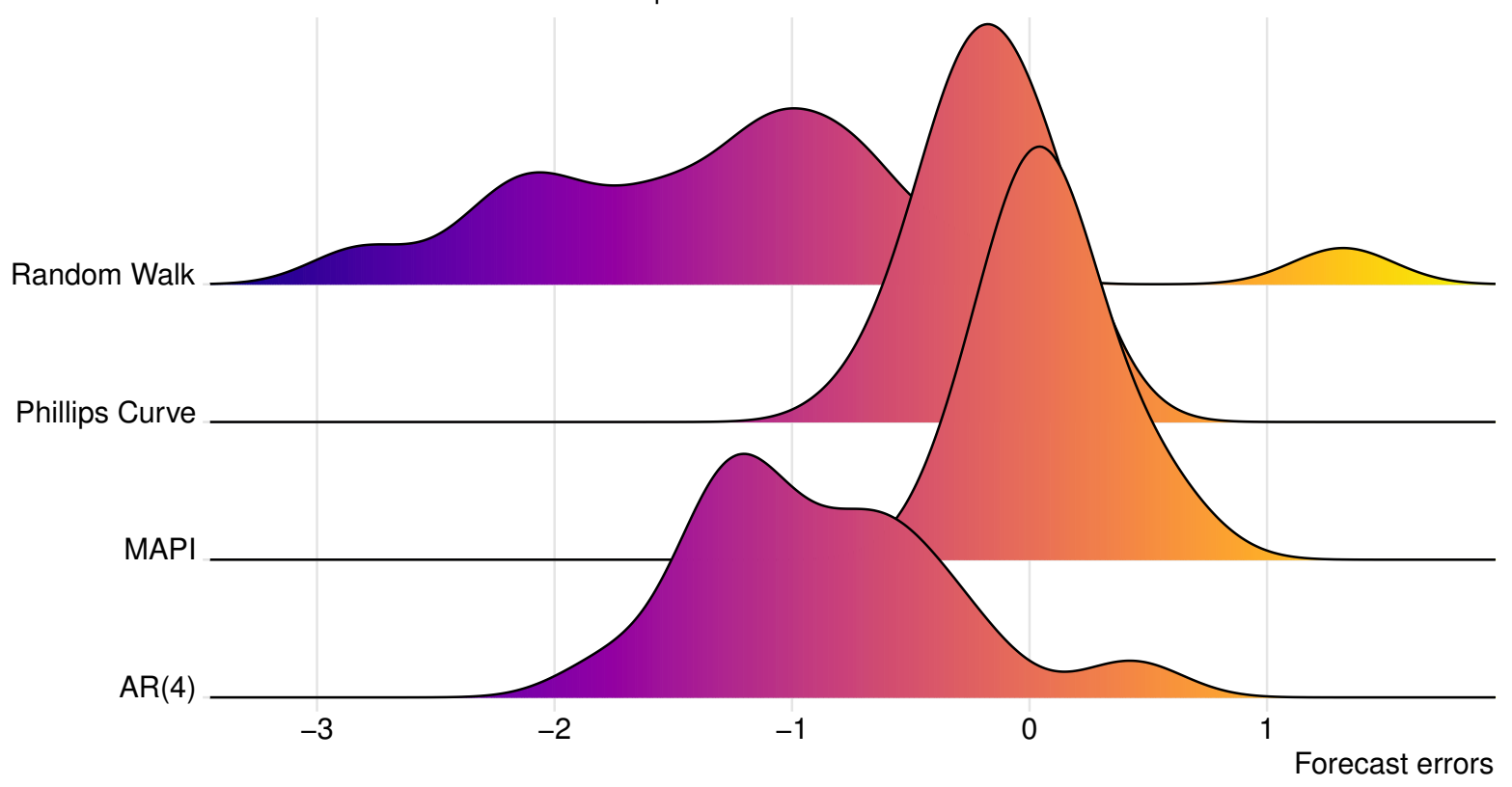

Comparison of the distribution of forecast errors from 2010Q1 to 2016Q4 at 12-quarter horizon for MAPI and benchmark models

Fig. 17. MAPI's forecasts of headline HICP

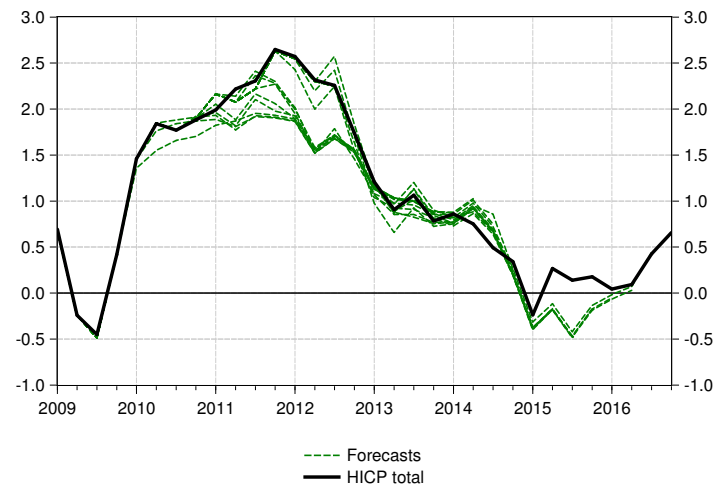

Fig. 18. MAPI's forecasts of excluding food and energy inflation

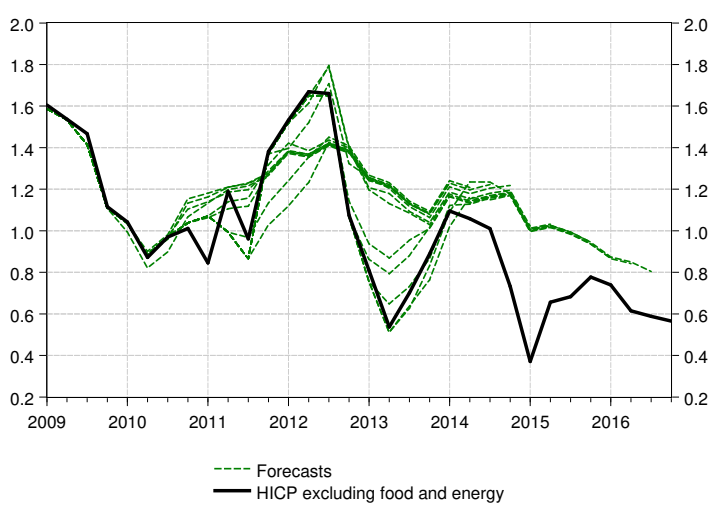


Fig. 19. Phillip's curve forecasts of headline HICP

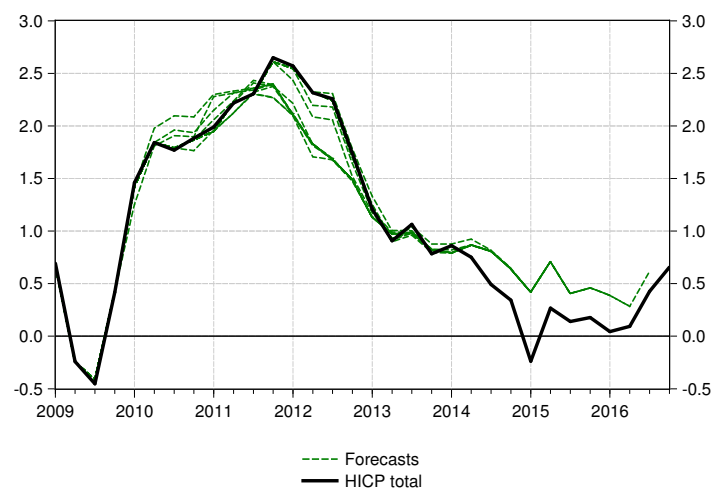

Fig. 21. AR(4) forecasts of headline HICP

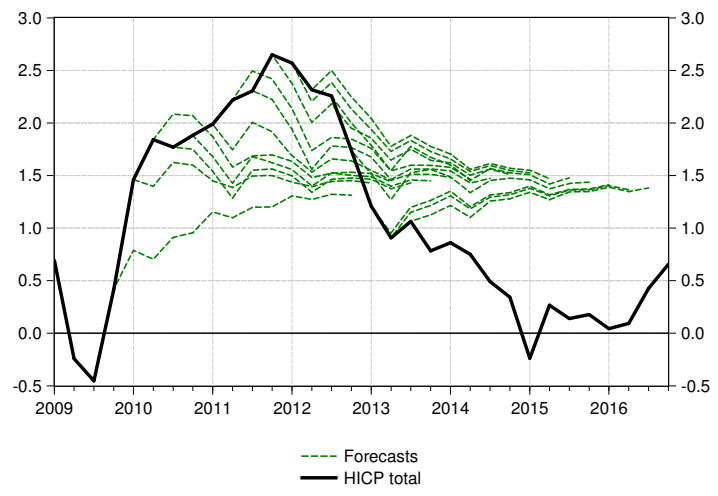

Fig. 20. Phillip's curve forecasts of excluding food and energy inflation

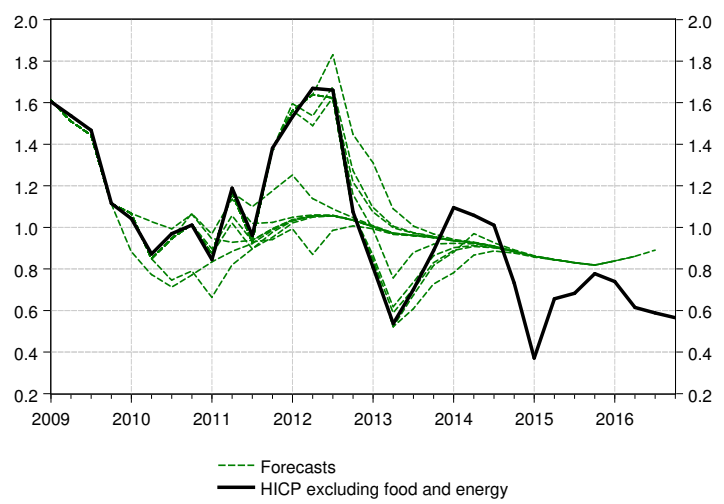

Fig. 22. AR(4) forecasts of excluding food and energy inflation

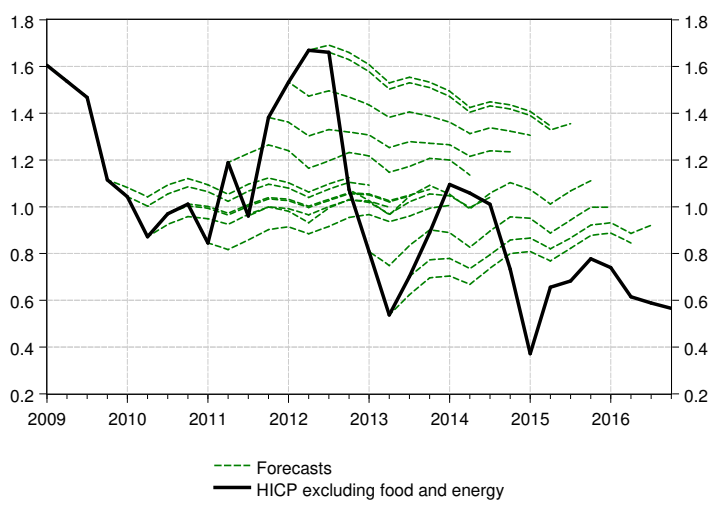




\section{Appendix B. Structure}

Figure pictures the models, the variables forecasted (background in green) and intermediate variables (background in grey) and exogenous variables from Mascotte (background in blue) and from the Eurosystem common assumptions (background in white).

Fig. 23. Structure of MAPI

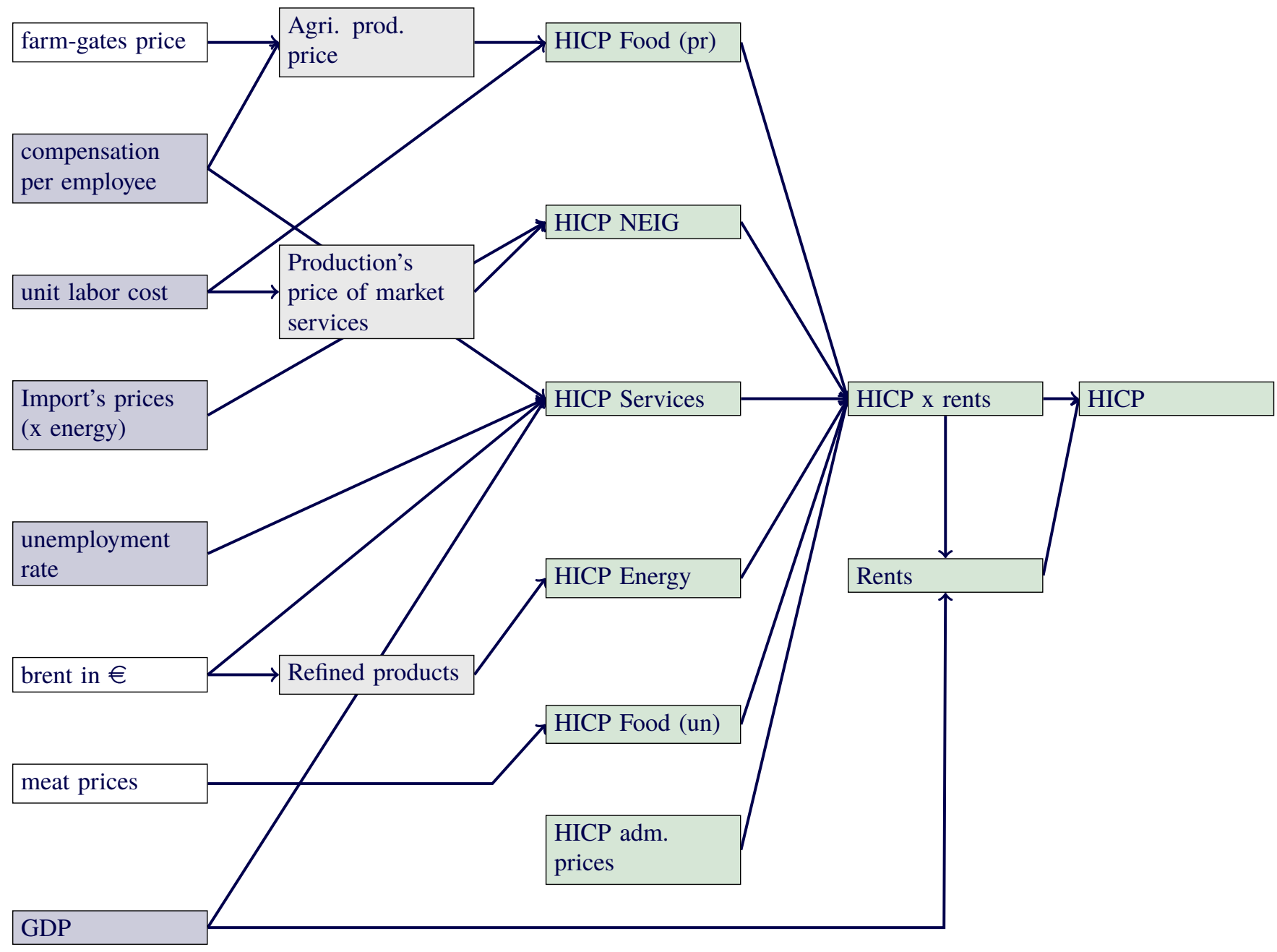




\section{Appendix C. Seasonal adjustment using a Kalman filter}

Seasonal adjustment is done using a Basic Structural Time Series Model Harvey, 1989. We seasonally adjust monthly time series. Quarterly seasonally adjusted time series are average of monthly time series. We model the time series $i_{t}$, the logarithm of a price index, as:

$$
i_{t}=\mu_{t}+\gamma_{t}^{1} * 1_{<2011}+\gamma_{t}^{2} * 1_{\geqslant 2011}+\epsilon_{t}
$$

where $\mu_{t}$ is the seasonal adjusted component, $\gamma_{t}$ the seasonal component; $\epsilon_{t}$ the error term and $1_{\geqslant 2011}$ accounts for the break in seasonality of price indexes in 2011 due to the introduction of the HICP Regulation on the treatment of seasonal products ${ }^{11}$. The time series components are unobserved and modeled by stochastic processes. The seasonally adjusted component is modelled as the sum of random walk and a trend.

$$
\mu_{t}=\mu_{t-1}+\alpha+\xi
$$

with $\xi \sim \mathcal{N}(0, \beta), \alpha$ captures the trend and is estimated by the Kalman's filter. The error term is a white noise:

$$
\epsilon_{t} \sim \mathcal{N}(0, \chi)
$$

The seasonal component is modelled using the Fourier decomposition of a seasonal signal. Let $\chi_{t}$ be a series of periodicity $T$, it follows from Dirichlet's theorem that it can be written as an infinite sum of Fourier series:

$$
X_{t}=\sum_{n=0}^{\infty}\left(a_{n} \cos \left(\frac{2 \pi n}{T} t\right)+b_{n} \sin \left(\frac{2 \pi n}{T} t\right)\right)
$$

For monthly data $a_{n}(n \geqslant 6)=0$, we also posit $a_{0}=0$ since we want seasonal factors to have a zero mean. Therefore (34) boils down to:

$$
\begin{aligned}
\gamma_{t}^{j} & =\sum_{i=1}^{6} \gamma_{i, t}^{j} ; j \in\{1,2\} \\
\text { with } \gamma_{i, t}^{j} & =a_{i} \cos \left(\frac{2 \pi i}{T}\right)+b_{i} \sin \left(\frac{2 \pi i}{T} t\right) \quad i \in \llbracket 1,6 \rrbracket
\end{aligned}
$$

Note that $\gamma_{i, t}^{j}$ is a series of periodicity $\frac{T}{i}$. Note that $\gamma_{i, t}^{j}$ can be written as:

$$
\left(\begin{array}{c}
\gamma_{i, t}^{j} \\
\gamma_{i, t}^{j *}
\end{array}\right)=\left(\begin{array}{cc}
\cos \lambda_{i} & \sin \lambda_{i} \\
-\sin \lambda_{i} & \cos \lambda_{i}
\end{array}\right)\left(\begin{array}{c}
\gamma_{i, t-1}^{j} \\
\gamma_{i, t-1}^{j *}
\end{array}\right) ; \lambda_{i}=\frac{\pi i}{6} ; i=1 \ldots 6
$$

With $\gamma_{i, 0}^{j *}=b_{i}$ and $\gamma_{i, 0}^{j}=a_{i}$.

Compared to Koopman and Franses, 2002, the seasonal component is non-stochastic to constrain the y-o-y change of the seasonal adjusted price index to be the same as the non-seasonally adjusted index.

\footnotetext{
${ }^{11}$ HICP Regulation No. 33/2009 on the treatment of seasonal products. For details, see the box entitled "Methodological changes in the compilation of the HICP and their impact on recent data", Monthly Bulletin, ECB, April 2011.
} 


\section{Appendix D. Petroleum products' equations}

This section shows the estimated coefficients for equations (17) and (18). The 6 equations were estimated on the sample 1999M01 - 2016M02.

Table 14: Coefficients for Petroleum products' equations

\begin{tabular}{lccccc|c}
\hline & $c_{s t}$ & $\gamma$ & $\alpha_{1}$ & $\alpha_{2}$ & $\gamma \beta$ & $R_{2}$ \\
\hline gasoline & 1.00 & -0.30 & 0.99 & 0.15 & n.a & 0.73 \\
diesel & 0.38 & -0.07 & 1.01 & n.a. & n.a. & 0.84 \\
fioul & 1.45 & -0.25 & 0.90 & n.a. & 0.009 & 0.91 \\
gazole & 2.12 & -0.29 & 0.90 & 0.10 & 0.004 & 0.93 \\
sp95 & 0.56 & -0.10 & 0.81 & 0.13 & 0.003 & 0.91 \\
sp98 & 0.48 & -0.08 & 0.80 & 0.14 & 0.005 & 0.92 \\
\hline
\end{tabular}




\section{Appendix E. Deriving a linear price from a Leontief produc- tion function}

This subsection outlines that the cost function is linear in price of inputs when the production function is Leontief.

A firm produces goods according to the following Leontief function:

$$
Y=A \min \left(\frac{K}{\alpha}, \frac{L}{\beta}\right)
$$

The production's function is not differentiable $\frac{K}{\alpha}=\frac{L}{\beta}$, however isoquants shows that optimum is obtained for $Y=\frac{K}{\alpha}=\frac{L}{\beta}$. The cost function writes:

$$
C(Y, w, r)=Y(\alpha r+\beta w)
$$

Fig. 24. Isoquants of a Leontief production function

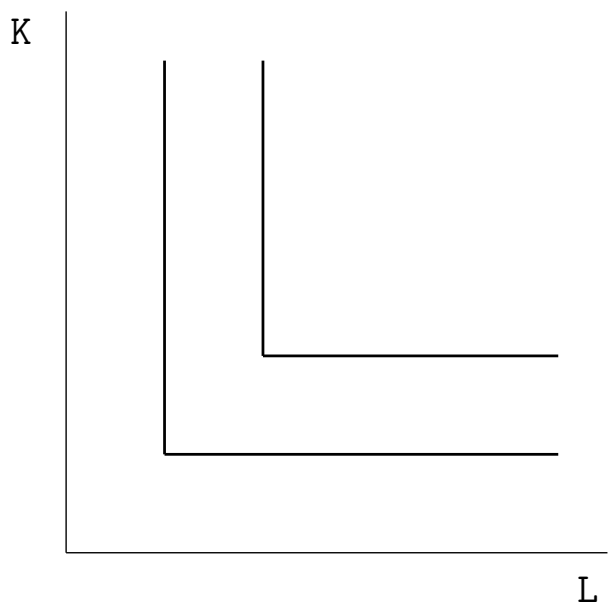




\section{Appendix F. Phillips Curve for headline and excluding food and energy inflation}

We follow Chatelais, Kalantzis, and de Gaye, 2015 and use the following specification for inflation:

$$
\Pi_{t}=\iota+\alpha \Pi_{t-p}+\beta x_{t-q}+\gamma \Pi_{t-r}^{m}+\epsilon_{t}
$$

with $\Pi_{t-p}$ the quarterly seasonally adjusted variation of headline HICP, $x_{t-q}$ the output gap and $\Pi_{t-r}^{m}$ a measure of imported inflation. For the headline inflation Phillips curve, $\Pi^{m}$ is the quarterly variation of the prices of imported goods and services relative to the quarterly variation of valueadded price. For the excluding food and energy inflation Phillips curve, $\Pi^{m}$ is the quarterly variation of the prices of imported goods excluding energy relative to the quarterly variation of value-added price

Table 15: Phillips curve's specification for headline inflation

\begin{tabular}{lcccc}
\hline & $\alpha(p=2)$ & $\beta(q=1)$ & $\iota$ & $\gamma(r=0)$ \\
& $0.12^{* * *}$ & $0.07^{* * *}$ & $0.38^{* * *}$ & $0.17^{* * *}$ \\
\hline$R_{2}$ & 0.60 & & & \\
Sample & $1996 \mathrm{Q} 4-2016 \mathrm{Q} 4$ & & \\
\hline
\end{tabular}

Notes: ${ }^{* * *}$ : pvalue $<0.01,{ }^{* *}$ : pvalue $<0.05,{ }^{*}$ pvalue $<0.1$

Table 16: Phillips curve's specification for excluding food and energy inflation

\begin{tabular}{lcccc}
\hline & $\alpha(p=1)$ & $\beta(q=1)$ & $\iota$ & $\gamma(r=2)$ \\
& $0.38^{* * *}$ & $0.03^{* * *}$ & $0.18^{* * *}$ & -0.02 \\
\hline$R_{2}$ & 0.35 & & & \\
Sample & $1996 \mathrm{Q} 4-2016 \mathrm{Q} 4$ & & \\
\hline
\end{tabular}

Notes: ${ }^{* * *}:$ pvalue $<0.01,{ }^{* *}:$ pvalue $<0.05,{ }^{*}$ pvalue $<0.1$ 


\section{Appendix G. Cointegration tests}

This appendix details the output of the tests of cointegration for each of MAPI's ECM. For each equation, we perform an Engle \& Granger test ${ }^{12}$ (see Engle and Granger, 1987).

\section{G.1. Unprocessed food}

Sample: 1998M01 2016M02

Included observations: 218

Null hypothesis: Series are not cointegrated

Cointegrating equation deterministics: $\mathrm{C}$

Automatic lags specification based on Schwarz criterion (maxlag=14)

Dependent tau-statistic Prob.* z-statistic Prob.*

LOG(I_A_SA) $\quad-2.936301 \quad 0.1305 \quad-17.40812 \quad 0.0870$

*MacKinnon (1996) p-values.

\section{G.2. Processed food}

\section{G.2.1. Processed food excluding tobacco}

Sample: 2000Q1 2014Q4

Included observations: 60

Null hypothesis: Series are not cointegrated

Cointegrating equation deterministics: $\mathrm{C}$

$\begin{array}{ccccc}\text { Dependent } & \text { tau-statistic } & \text { Prob.* }^{*} & \text { z-statistic } & \text { Prob.* } \\ \text { LOGIBHTSA } & -2.701314 & 0.5858 & -34.72931 & 0.0073\end{array}$

*MacKinnon (1996) p-values.

\footnotetext{
${ }^{12}$ The number of lags is selected by Schwarz criterion
} 


\section{G.2.2. Production price in the agrifood sector}

Sample: 2000Q1 2014Q4

Included observations: 60

Null hypothesis: Series are not cointegrated

Cointegrating equation deterministics: $\mathrm{C}$

$\begin{array}{ccccc}\text { Dependent } & \text { tau-statistic } & \text { Prob.* } & \text { z-statistic } & \text { Prob.* } \\ \text { LOGPPRODC1 } & -3.009721 & 0.2607 & -25.04546 & 0.0327\end{array}$

*MacKinnon (1996) p-values.

\section{G.3. Manufactured Products}

\section{G.3.1. Production's price of market services}

Sample: 1998Q1 2014Q4

Included observations: 68

Null hypothesis: Series are not cointegrated

Cointegrating equation deterministics: $\mathrm{C}$

Automatic lags specification based on Schwarz criterion (maxlag=10)

$\begin{array}{ccccc}\text { Dependent } & \text { tau-statistic } & \text { Prob.* } & \text { z-statistic } & \text { Prob.* }^{*} \\ \text { LOG(DEFL_PROD_DSM/CSU_CICE) } & -3.190071 & 0.0845 & -13.53155 & 0.1671\end{array}$

*MacKinnon (1996) p-values.

\section{G.3.2. Manufactured products}

Sample: 1996Q1 2014Q4

Included observations: 76

Null hypothesis: Series are not cointegrated

Cointegrating equation deterministics: $\mathrm{C}$

Automatic lags specification based on Schwarz criterion (maxlag=2)

Dependent tau-statistic Prob.* z-statistic Prob.*

$\begin{array}{lllll}\text { LOGICXPPSA } & -3.378443 & 0.1363 & -28.06377 & 0.0193\end{array}$

*MacKinnon (1996) p-values. 


\section{G.4. Services}

The private services long run equation posits a cointegration between private services and compensation per employee. In order to verify the soundness of this hypothesis, we perform a unit root test on the residuals of the long run equation.

Null Hypothesis: RESID_SER_LT has a unit root

Exogenous: Constant

Lag Length: 0 (Automatic - based on SIC, maxlag=11)

\begin{tabular}{lccc}
\hline & t-Statistic & Prob.* \\
\hline Augmented Dickey-Fuller test statistic & -2.794822 & 0.0638 \\
Test critical values: & 1\% level & -3.520307 & \\
& 5\% level & -2.900670 & \\
& 10\% level & -2.587691 & \\
\hline
\end{tabular}

*MacKinnon (1996) one-sided p-values. 